SUSTAINABLE DEVELOPMENT IN AGRICULTURE AND INFORMATION \&COMMUNICATION TECHNOLOGY SENSOR NETWORKS

\author{
by \\ Junyi Liu \\ BSc in Science, Nanjing Forestry University, Nanjing, 2016
}

\author{
A Master's Research Paper \\ presented to Ryerson University \\ in partial fulfillment of the \\ requirements for the degree of \\ Master of Applied Science \\ in the program of \\ Environmental Applied Science and Management
}

Toronto, Ontario, Canada, 2020

CJunyi Liu, 2020 


\section{Author's Declaration}

\section{AUTHOR'S DECLARATION FOR ELECTRONIC SUBMISSION OF A PROJECT PAPER}

I hereby declare that I am the sole author of this project paper. This is a true copy of the project paper, including any required final revisions.

I authorize Ryerson University to lend this project paper to other institutions or individuals for the purpose of scholarly research.

I further authorize Ryerson University to reproduce this project paper by photocopying or by other means, in total or in part, at the request of other institutions or individuals for the purpose of scholarly research.

I understand that my project paper may be made electronically available to the public. 


\title{
SUSTAINABLE DEVELOPMENT IN AGRICULTURE AND INFORMATION \&COMMUNICATION TECHNOLOGY SENSOR NETWORKS
}

\author{
Junyi Liu \\ Master of Applied Science \\ Environmental Science and Management \\ Ryerson University, 2020
}

\begin{abstract}
This study answered the question of how to use ICT sensor networks to increase crop yields, while reducing agricultural inputs and the associated negative ecological impacts. According to the model built for simulating a farm, if the average farm uses ICT sensor networks to simultaneously monitor and control the amount of irrigation water, fertilizer and pesticides, the farm's crop yield can increase by $16 \%$ and consumption of agricultural inputs can be reduced by $20 \%, 14 \%$ and $25 \%$, respectively. The results of this study have important implications for improving the yield and productivity of farming, and for the sustainable development of agriculture. The effects of the climatic zones in which the farms are located on performance of ICT sensor networks proved to be statistically insignificant.
\end{abstract}

\section{Keywords}

sustainable development; agriculture; information and communication technology; ICT; crop yield; predictive analysis; simulation 


\section{Acknowledgements}

I would like to express my great gratitude to my supervisor Dr. Farid Shirazi, who has patiently guided and encouraged me to pursue this master's degree in the past three years. Dr. Shirazi was always supportive whenever I ran into a trouble spot or had a question about my research.

I would like to express sincere appreciation to Dr. Andrew Laursen. Once upon a time, I used to feel quite helpless about my study. Dr. Laursen generously provided me with guidance, encouragement, and comments that benefited me very much.

I would like to give special thanks to my family, my friends, and my cat for all the support and love you have shown me through these years. 


\section{Table of Contents}

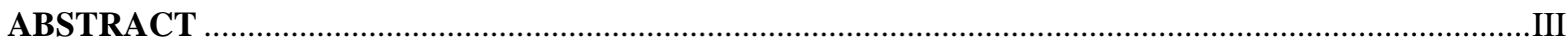

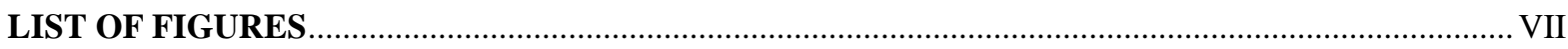

LIST OF APPENDICES ............................................................................................................

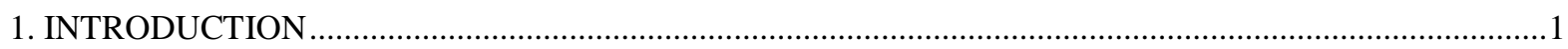

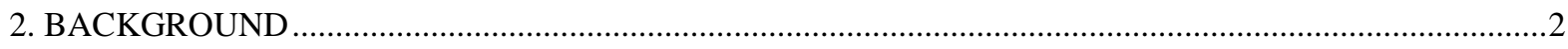

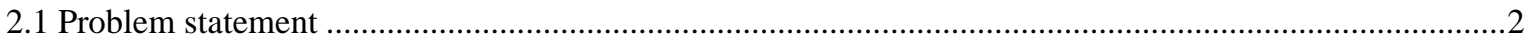

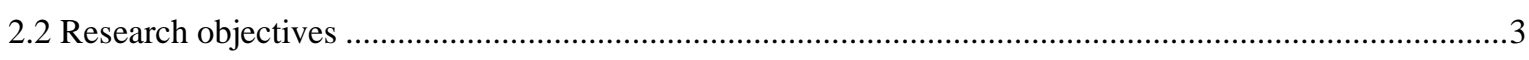

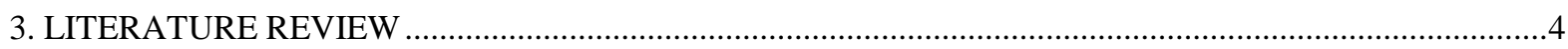

3.1 Sustainable Development and ICT sensor networks .............................................................................

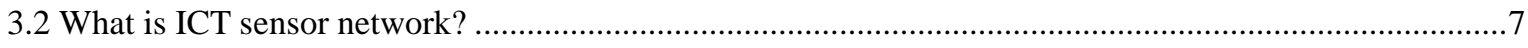

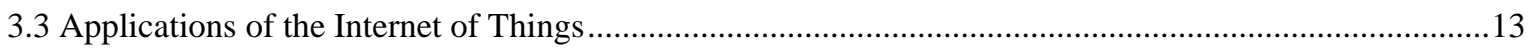

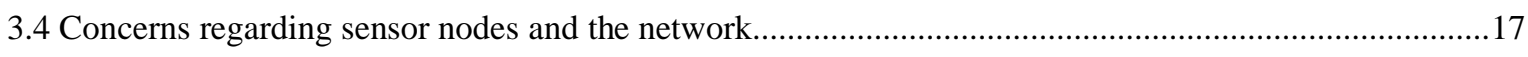

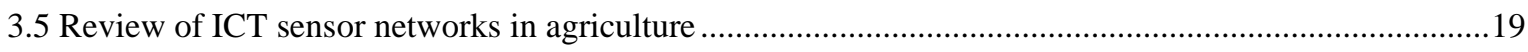

3.6 How do crops interact with the external environment? ............................................................................22

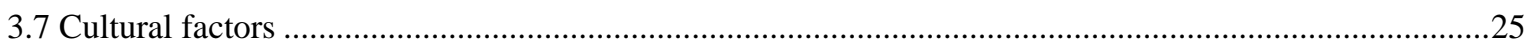

3.8 Integration of sensor networks with other ICT products for boosting production in agriculture ...............26

3.9 A case study illustrating use of UAV and ICT sensor networks in sustainable agriculture ........................31

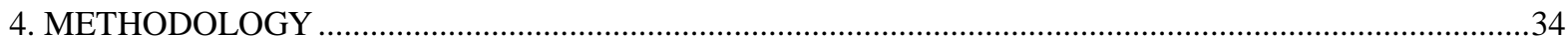

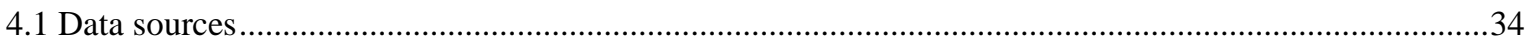

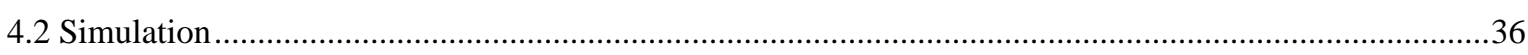

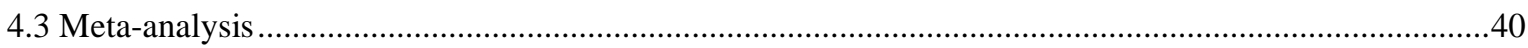

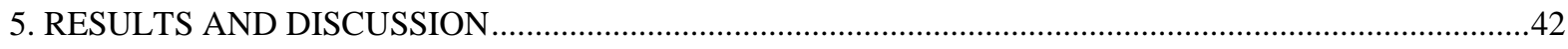

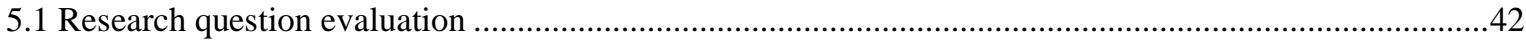

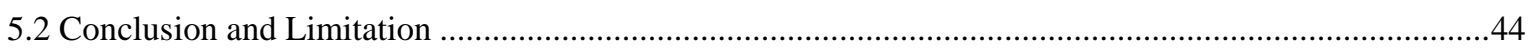

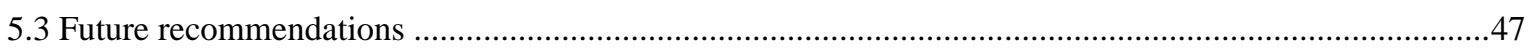

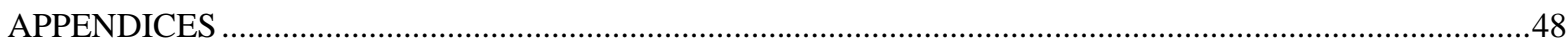

Appendix A: Tables and figures of the details of ICT sensor networks........................................................48

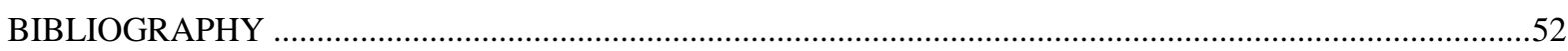




\section{List of Tables}

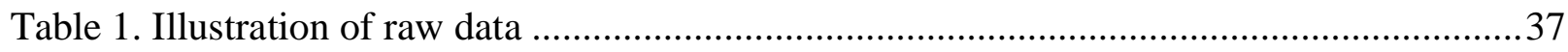

Table 2. Data collected from publications. The missing values estimated by missForest are

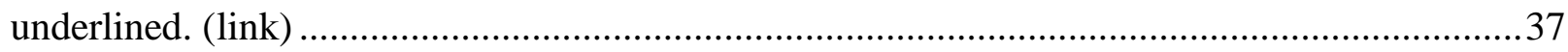

Table 3. Result of Test of between-subjects effects from SPSS .......................................42 


\section{List of Figures}

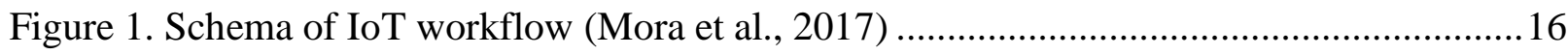

Figure 2. Three-tiered UAV farmland sensor network by Zhang et al. (2015) ...........................28

Figure 3. Map after the application of the interpolation technique (Faiçal et al., 2014) ..............33

Figure 4. Map after the application of the threshold value (Faiçal et al., 2014) ..........................33

Figure 5. Geographical distribution of the farms involved .........................................................34

Figure 6. Estimated production of principal field crops of Canada (Statistics Canada, 2019) ...44 


\section{List of Appendices}

Figure A1. Architecture of wireless sensor networks based on fog network (Telecommunication Standardization Sector of International Telecommunication Union, 2014) .................................48

Figure A2. Major components of nodes in ICT sensor networks (Sliva, 2008)..........................49

Figure A3. Architecture of nodes in ICT sensor networks (El-Kader \& El-Basion, 2013) ........49

Figure A4. Comparison of available wireless protocols (Sohraby , Minoli, \& Znati, 2007) ......50

Table A1. Comparison of communication protocols (Ojha, Misra, \& Raghuwanshi, 2015) .....50

Table A2. Examples of ecological sensors (Gong, 2010) .......................................................51 


\section{Introduction}

As is advocated by the United Nations, efficiency of the life cycle of production process is an important consideration for sustainable development. This study aims to quantitatively assess the degree to which Information and Communication Technologies (ICT) sensor networks can help increase crop yield in farmland and cut down on the consumption of resources. Additionally, in agriculture, excessive application of nutrients can be regarded as pollution. Therefore, pollution prevention is an additional consideration in sustainable agricultural development. An ICT sensor network is an effective tool to monitor external conditions and collect data for making decision for agricultural inputs allocation (i.e., watering, fertilizer application, and pesticide application) for optimal outcome (i.e., crop yield).

In this study, a model to simulate the performance of farms that are equipped with ICT sensor networks for controlling usage of agricultural inputs, with the data collected from publications and from the service providers that focus on utilizing ICT sensor networks in agriculture. With the model, an estimated value of possible outcomes (crop yield, resource inputs) was calculated.

This study answered a question that how to use existing technologies to increase crop yields, while reducing agricultural inputs and the associated negative ecological impacts. The results of this study have important implications for improving the yield and productivity of farming, and for the sustainable development of agriculture. The effects of the climatic zones in which the farms are located on performance of ICT sensor networks are also analyzed, and the influence of location variation proved to be insignificant. 


\section{Background}

\subsection{Problem statement}

A growing population and the corresponding needs for food throughout the world have prompted farm owners to expand the scale of planting. As farm size expands, it is no longer feasible to rely on collecting data manually for making decisions on agricultural activities (Brase, 2006). Breakthroughs in areas of information technology, lower manufacturing and usage cost, smaller size, and longer life span have made sensors ubiquitous items for the public (Nack, 2019), and there has been a trend that ICT sensors technologies are being widely applied in agriculture, controlling the usage of water, fertilizer, and pesticide. Meanwhile, in many studies that discussed wireless sensor networks in farms, the effects of using this service were not clearly mentioned. To describe the performance of ICT usage on farms, two types of information (indicators) should be provided: the percentage of agricultural resources that can be saved, and the increase in crop yield that are realized by using wireless sensor networks. Some of the articles listed both indicators, while some of them only provided one or neither of these indicators.

Many previous studies on sensor networks in agriculture have focused mainly on the deployment and configuration of wireless sensor networks, and the collection of environmental data. Work by Sakthipriya(2014) is a typical example. In the study by Sakthipriya(2014), a crop management system has two types of functions, sensing and decision making. The sensor network can collect environmental parameters including temperature, soil moisture and soil $\mathrm{pH}$ value. Based on these environmental parameters sent to the backbone, decisions on whether the water sprinkler should be turned on to provide sufficient water to the field can be made.

However, there has been little quantitative analysis on the potential of wireless sensor networks to enhance crop yield or improve efficiency of resource use. Most of the studies claim that the wireless sensor networks solution they discussed will improve or boost the crop production. iFarm designed by Jiber et al. (2011) is a typical example. This system provided irrigation management (monitoring and controlling water usage), pest and disease detection, crop yield prediction, and resource optimization. Few studies provided the percentage or incremental gain in crop production and saving on agricultural inputs. For example, Xiong et al.(2008)collected a variety of environmental and animal-related data (e.g. breed, days in milk, 
milk time, milk quality, reproduction status, location), but further utilization of the data in predicting animal activities or future production was not carried out.

\subsection{Research objectives}

The overall purpose of my study is to evaluate how the farmland and crop would respond, when wireless sensor networks are deployed to monitor and control how much water, fertilizer, and pesticide are used. I decided to carry out research based on the performance data collected from existing farms using this type of service. The goal of my research is to determine the quantitative relationships between use of wireless sensor networks and performance indicators (change in crop yield and agricultural resource usage on farms). The analysis is based on existing farms that have already been equipped with wireless sensor networks and that have collected performance indicator data.

Therefore, my major research questions are:

(1) To what degree can ICT sensor networks boost crop yield by monitoring and controlling the usage of water, fertilizer, and pesticide?

(2) If ICT sensor networks could be deployed throughout a selected country or area, how could the annual yield of crops change? 


\section{Literature review}

In this literature review, concepts of sustainable development, an introduction to ICT sensor network, and applications of ICT sensor networks are discussed.

\subsection{Sustainable Development and ICT sensor networks}

\subsubsection{Overview of sustainable development}

The United Nations in 1987 articulated a need "to make development sustainable to ensure that it meets the needs of the present without compromising the ability of future generations to meet their own needs" (World Commission on Environment and Development, 1987). This concept drew the attention of the public toward finding ways to avoid sacrificing the natural environment for economic growth. Over time, given the changing needs of people with respect to the environment, society and economy, the practices and definition of sustainable development need to be up-to-date.

The US Department of Agriculture and the Environmental Protection Agency defined sustainable agricultural development as "Agricultural sustainable development refers to the application of local intrinsic technology to achieve the following objectives for a long time and strive to form a comprehensive production system for plant and livestock production." (Hebei Academy of Social Sciences, 2017). These objectives include (1) to meet the needs of people's food and clothing; (2) to improve the quality of the environment and natural resources on which agricultural production depends; and (3) to make the most efficient use of non-renewable resources and materials available on farms, and at the same time, comprehensive regulation of natural resources management methods is carried out if necessary; (4) maintaining the economic vitality of agricultural production entities; and (5) improving the overall quality of life of farmers and the whole society (Hebei Academy of Social Sciences, 2017).

A report from the United Nations claims that if the global population increases to 9.6 billion in the next 30 years, the equivalent of three planets would be required to meet the demands of humans given current lifestyles (United Nations, 2016). Facing the challenge of fulfilling growing demands with limited resource, it is essential to increase the efficiency of using resources, so the United Nations proposed a concept of Sustainable Consumption and Production. Based on the principle of higher efficiency with smaller input and more output, this 
concept improves the quality of life while reducing resource consumption and environmental degradation and pollution levels throughout the consumption and production cycle, thereby enhancing the welfare benefits of economic activities (United Nations Environment Programme, 2010).

In 2015, the General Assembly adopted 17 Sustainable Development Goals for the following 15-year lifespan, aiming to achieve sustainable development inclusively for everyone. Among the 17 goals, Sustainable Development Goal 12 (also known as SDG 12) is most related to this study. SDG 12 was to build a more sustainable and production-efficient world. Its major targets include (1) promoting resource and energy efficiency, and (2) promoting sustainable infrastructures (United Nations, 2015). The SDGs were intended to promote a new worldview and provide the beginnings of a plan to end poverty without imposing significant costs on Earth's life-support systems. The goals may help create a fresh global narrative around a common future to mobilise collective action and help develop a shared understanding of interconnected risks and solutions(Gaffney, 2014).

\subsubsection{Agricultural waste issues}

Higher production and smaller input are required for sustainable development. To meet the demand for food by a growing global population, an expansion in agricultural production is needed. As farm sizes expand, it is no longer viable to rely on collecting data manually for making decisions on agricultural activities (Brase, 2006). At the same time, various sensors which have lower manufacturing and utilization costs, smaller size, and longer life spans, have become ubiquitous items for the public (Nack, 2019).

Another aspect of accomplishing United Nation's SDG 12 is to reduce the solid waste that is generated from production processes, which could cut down on the amount of raw materials that manufacturers have to obtain from nature or artificially create (Bishop, 2004).Relevant to this research is agriculture waste, produced by agricultural activities. Agricultural waste is comprised of animal waste (manure, animal carcasses), food processing waste (only $20 \%$ of maize is canned and $80 \%$ is waste), crop waste (corn stalks, sugarcane bagasse, drops and culls from fruits and vegetables, pruning) and hazardous and toxic agricultural waste (pesticides, insecticides and herbicides, etc.) (Ramírez-García et al., 2019; Obi et al., 2016). 
Most chemicals of agricultural waste are water-soluble and can leach and enter water bodies and food, leading to severe ecologic and human health impacts. This can cause serious health disorders in humans, including cancer, Parkinson's disease, Alzheimer's disease, birth defects, and reproductive disorders. Pesticides can also kill non-target plants, birds, and other wildlife, and have a significant negative impact on soil quality and fertility (Ramírez-García, Gohil, \& Singh, 2019).

Fertilizer contains massive amount of nutritive minerals including nitrogen, phosphorus, and potassium which provides support for plants to grow faster and increase yields. However, if the application of fertilizer surpasses the crop/soil system's capacity to absorb the nutrients, the excessive minerals will leak into surface runoff, and eventually enter waterbodies such as lakes, rivers, creeks, etc. (Karunanithi et al., 2016). When the excessive NPK minerals enter the waterbody, eutrophication occurs, with mass production of photosynthetic microorganisms. When these photosynthetic microorganisms die, bacteria activity decomposing this biomass can deplete dissolved oxygen, causing other organisms such as fish to die of hypoxia (Wetzel, 2001).

United States Environmental Protection Agency recommended the following ways to mitigate the pollution by excessive agricultural inputs: (1) applying nutrients in the right amount, at the right time of year, with the right method and with the right placement; (2) Ensuring year-round ground cover to avoid soil erosion and nutrients loss to the waterway; (3) Planting field buffers. Planted buffers can help prevent nutrient loss from fields by absorbing or filtering out nutrients before they reach a water body; (4) Installing fence along waterways to keep animals off the stream, river, etc. (United States Environmental Protection Agency, 2019)

In the context of this study, ICT sensor networks are deployed on farms to collect information about the factors that would affect crop yield, such as soil water content, fertilizer usage, and soil/atmospheric temperature (Meeradevi \& Mundada, 2015). Once information has been collected, it can be processed in two different directions. The first is that information can be sent directly to terminal clients and then converted into graphic deliverables by visualization software. With visualized content about the farm environment, farm managers would know better about how the farm works, and what kind of strategies they should take for better or more 
efficient crop production. The second direction focuses on the idea of agricultural resource and waste control. The sensor network keeps contributing to making decision on the ground regarding the proper amount of water, fertilizer and pesticide to be applied on site.

\subsection{What is ICT sensor network?}

Information and Communication Technology is a varied cluster of digital tools and resources used to communicate, generate, disseminate, store and perform information management (Rahman et al., 2016).

\subsubsection{Internet of Things}

In this study, the main infrastructure used for improving production is the sensor network. The ICT sensor network is a subset of the Internet of Things (IoT), referring to the interconnection of smart devices, ranging from appliances to tiny sensors (Stallings \& Brown, 2018). An advantageous feature of the Internet of Things is that short-range mobile transceivers are embedded in various gadgets and daily necessities, thereby enabling new forms of communication between people and things, and between things. The cloud systems today support the interconnection of billions of industrial and personal objects. These objects can pass information collected from distributed sensor nodes. Utilizing this low-latency information can be used to effectively monitor the environment and make decisions for overall management of large systems such as factories or cities. The farms involved in this study are benefiting from this technology. From the initial PC and server to later professional operational technology and personal electronic communication equipment, sensor-based internet of things represents the latest products and trends of the Internet (Stallings \& Brown, 2018).

The sensor nodes are the most basic and underlying devices of an Internet of Things, and at the same time they represent one of the core technologies of the wireless sensor networks for this study. A single sensor unit consists of five key components, sensor, actuator, microcontroller, transceiver and radio-frequency identification (Stallings \& Brown, 2018), which will be discussed in a following subsection regarding sensor node structure.

In the context of a complete enterprise network, an Internet of Things may have four different layers. The bottom-up order of these layers is the edge layer, the fog layer, the core layer and the cloud layer. The edge layer is mainly composed of sensors and switches, which 
can communicate information to each other when needed. At this layer, there are a few gateways that connect sensors to communicate with higher-level networks. After the data is collected by the gateway, it is transmitted to the fog layer. The amount of data this layer receives from distributed sensor networks on the ground is usually very large, so a significant feature of the fog layer is that it can be evaluated close to the edge layer. This can effectively reduce the pressure on the entire network from transmitting a large amount of data, whether it consumes bandwidth or consumes other resources. The main functions of the core layer above the fog layer are to connect the broadly distributed fog layer, and to open the interface to external servers. The cloud layer on the top of the network, provides storage and processing capabilities for large amounts of aggregated data sensor nodes from the edge (Stallings \& Brown, 2018).

\subsubsection{Network structure and architecture}

The realm of wireless networks can be divided into infrastructured and infrastructureless networks. A typical infrastructured wireless network consists of a central base station where all the information transmitted from the ground is processed, and nodes collect information at ground level. A cellular wireless network is the most common type of infrastructured network. Different from the infrastructured network, an infrastructureless wireless network has distributed, independent, dynamic topology, low-power, task-oriented wireless nodes. With these features, a lot of decisions can be made at ground level, and as a result, some unnecessary information for high-level decision-making will be removed from the information package which will be sent to a central base station (Jangra, 2010). The wireless sensor networks to be discussed in this study is a typical instance of an infrastructureless network.

Stallings and Brown (2018) summarized a sensor network as a cluster of sensors transmitting their data to one intermediate entity that aggregates the data to be collected by a higher-level entity. There are five steps that a sensor network should take when a sensor node has fetched data from an external environment:

(1) Evaluation: evaluating data for criteria as to whether it should be processed at a higher level.

(2) Formatting: reformatting data for consistent higher-level processing. 
(3) Expanding/decoding: handling cryptic data with additional context (such as the origin).

(4) Distillation/reduction: reducing and/or summarizing data to minimize the impact of data and traffic on the network and higher-level processing systems.

(5) Assessment: determining whether data represent a threshold or alert; this could include redirecting data to additional destinations.

An advantage of the four-layered architecture of the Internet of Things networks, is that the size of data packets to be transmitted gradually shrinks as data moves from ground level to the higher levels (Stallings \& Brown, 2018).

Another distinguishing characteristic of a sensor network is fog computing, which is an opposite technical trend to cloud computing. Cloud computing refers to the network that makes massive and centralized storage, and processing resources available to distributed users or clients. In fog computing, many smart devices (e.g. sensors) are interconnected by fog network facilities that provide data processing function which is close to the sensors rather than the higher-level devices (Stallings et al., 2012). In terms of the efficiency, the fog network between the smart devices layer and the core network layer enables lots of vital decisions to be made by the smart devices on the edge. That is to say, the time it takes for sensed data at ground/edge to travel to the higher-level cloud server can be saved by processing in the fog network. The architecture of the IoT equipped with a fog network relieves the burden of computing in the central part of the IoT system, which in turn allows more smart devices to be engaged in the network. Owing to the rapid detection or rapid measurements of sensors on edge, the risk of disaster from a cascading system failure would be decreased, and therefore the potential costs to maintain and repair the system would be saved (Cisco, 2015). Sliva's research on WSNs includes a five-layered protocol, including a physical layer, a data link layer, a network layer, a transport layer and an application layer (Sliva, 2008).Appendix Figure A1 is a common architecture of ICT sensor network (Telecommunication Standardization Sector of International Telecommunication Union, 2014). The multi-layer feature of a sensor network is clearly illustrated in Appendix Figure A1. 


\subsubsection{Sensor node structure}

Nodes are a fundamental part of a viable wireless sensor network. There are four major components in a node which are a power unit (e.g. battery sets), sensing unit, processing and storage unit and transceiver unit (for communication), with the major structure of a node depicted according to Sliva (2008)(Appendix Figure A2), and a more detailed explanation (ElKader \& El-Basion, 2013) (Appendix Figure A3). In a fog network, these nodes have an additional component, the microcontroller, which is the intelligence for making basic decisions at ground level of a whole network.

To ensure a sufficiently long network life, energy efficiency in all parts of the network is critical. Therefore, data processing tasks are often spread across the network: that is, nodes need to cooperate to transmit data to receivers (Galar \& Kumar, 2017).

In real-world application of wireless sensor networks in agriculture, one of the main concerns and barriers is that the farm owners or operators would worry about the costs of running the network in fields, which includes the initial expense of setting up and configuring hardware, the costs of maintenance and replacement, and of electricity for devices in the long run (Sliva, 2008; El-Kader \& El-Basion, 2013). In order to minimize the costs of nodes, more circuits should be integrated into each chip. Regarding the energy, less memory and less powerful processing units in ground devices can be used to reduce cost (Sliva, 2008). This strategy makes sense, but at the same time it would increase the burden of computing in a central base station, and in turn slow down the speed of processing data and making decisions.

\subsubsection{Wireless standard used in ICT sensor networks}

At present, there are many standards and protocols for the wireless transmission of signals in wireless sensor networks. Among them, the following protocols are the most frequently used(Sohraby, Minoli, \& Znati, 2007):

- IEEE 802.15.1 (also known as Bluetooth);

Bluetooth is a standard for short range, low power, and low-cost wireless communication that uses radio technology. Its short-range wireless capability allows peripheral devices to communicate over a single air-interface, replacing the cables that 
use connectors with a multitude of shapes, sizes and numbers of pins (McDermott-Wells, 2004).

- IEEE $802.11 \mathrm{a} / \mathrm{b} / \mathrm{g} / \mathrm{n}$ series of wireless LANs;

IEEE 802.11 and $802.11 x$ refers to a family of specifications developed by the IEEE for wireless local area network (WLAN) technology. 802.11 specifies an over-the-air interface between a wireless client and a base station or between two wireless clients (IEEE Standard Association, 2020).

- $\quad$ IEEE 802.15.4 (ZigBee);

ZigBee is a specification for a suite of high-level communication protocols using lowpower digital radios based on IEEE 802.15.4. The technology defined by the ZigBee specification is intended to be simpler and less expensive than the other consumer wireless personal area networks, such as Bluetooth. A distinguishing feature of ZigBee is low cost, which allows this technology to be widely used in the area of wireless controlling (Radmand, Talevski, Petersen, \& Carlsen, 2010).

- $\quad$ MAN-scope IEEE 802.16 (WiMAX);

WiMAX standard is a family of 802.16 , that provides, multiple physical layer (PHY) and Media Access Control (MAC) options (Nuaymi, 2007).

- Radio-frequency identification (RFID) tagging.

There are two general categories of RFID tagging, active and passive, depending on their source of electrical power. Active RFID tags contain their own power source, usually an on-board battery. Passive tags obtain power from the signal of an external reader. This technique has been used widely in the areas of supply chain management, security, and movement tracking (Weinstein, 2005).

These transmission protocols and their corresponding properties, including transmission range and speed, have been summarized in previous literature (Sohraby et al., 2007; Ojha et al., 
2015). When configuring transmission protocols for WSNs, the person who makes the decision should select the appropriate one based on energy availability, nodes characteristics, and performance requirement of this network. Appendix Figure A4 and Appendix Table A1 show the differences in data transmission rate, transmission range, and energy consumption of these available transmission protocols.

The technologies described above enable many sensors to be deployed in crop fields in a non-destructive way, which in turn helps increase the resolution when mapping soil, plant, and livestock properties.

\subsubsection{Energy efficiency matters}

The energy consumed by an ICT sensor network mainly has two aspects, the direct current brought by the battery used by the node, and the alternating current consumed by the data center or core layer of the network when processing data. A technology used to facilitate sustainable development should be in line with its own idea of sustainable development. Therefore, energy efficiency in ICT sensor networks should be considered. Improving energy efficiency in the ICT solutions requires both policy and technology guidelines (Cremer et al., 2010). In terms of technologic guidelines, these solutions start with where the ICT industry consumes energy. For example, server clusters, data centers, and base stations that are now commonly used consume electric power for daily operations on the one hand, and cooling hardware on the other(Fagas, Gammaitoni, Gallagher, \& Paul, 2017). For energy consumed to maintain daily operations, the base station should first ensure that there are no in-situ servers that are powered on but not working at all. The second step is to transform the traditional data centers into next generation hyperscale data centers. This upgraded data center has $25 \%$ higher energy efficiency than the traditional one. From 2016 to 2020, a hyperscale data center is predicted to shrink the overall energy consumption by 50\%, with these small and less-efficient data centers shut down (Jones, 2018).

Tackling cooling down or maintaining system temperature is another technical improvement direction. Monitoring real-time operation conditions including temperature and humidity makes it possible to make dynamic actions on the right timing to run a cooling system. 
This practice can avoid excessive cooling when the workload in the data center is not heavy (Shuja et al., 2012).

Optimizing computing procedure and network architecture is another guideline for higher efficiency. For example, streamlining the computing process, scaling dynamic voltage and frequency for high-performance tasks, and balancing the data pipeline are all feasible options for architecture (Fagas et al., 2017; Satran, 2018). However, implementing these measures to improve the energy efficiency of ICT sensor networks will inevitably encounter obstacles. As is mentioned above, guidelines for improving energy efficiency in ICT industry impact initially the businesses from an economic perspective, and it will inevitably add financial burden to both business owners and their clients/consumers. For instance, adding taxes or extra fees to the price of a product is never an easy task, because the stakeholders might be reluctant to accept this increase in cost.

In terms of deploying advanced cooling systems for higher energy, this practice has two major obstacles for implementation. The first one is the price that data centers have to pay for this upgrade, because cost-controlling is the very basis of running business in a robust manner. Another barrier is that some smart temperature controlling systems that are integrated into data centers involve deep customization for better compatibility. Therefore, it will take time and efforts to set up such a system for a data center.

The third guideline mentioned above may have technical difficulty in implementing, that is the transformation and upgrading of legacy architecture and computing algorithms is a mentally work-intensive job, and it requires massive assistance from external sources. If so, further collaboration between internal and outsourced workers will cost time and effort for this integration.

\subsection{Applications of the Internet of Things}

Internet of Things has been applied in various industries, including but not limited to grid, transportation, logistic and healthcare (Wu, 2010). This study mainly discusses the application of IoT in healthcare and finance. 


\subsubsection{The Internet of Things in Healthcare}

The Internet of Things solutions for healthcare includes the following aspects, equipment for patients, equipment designed for doctors' work, and networks for hospital management.

Internet of Things for patients. IoT solutions for monitoring the health or medical conditions of individuals are able to collect parameters from patients, using the body-sensor nodes that are equipped in wearable devices. These solutions play an important role in improving the quality of life and survival opportunities of critically ill patients and chronically ill patients. Fortino et al. (2014)designed a body sensor networks called BodyCloud, which can gather real-time data regarding body temperature, blood pressure, and electrocardiography, and conduct further processing on raw data, data storage and analysis. Fanucci et al (2012)created a system to monitor the vital signs of chronic heart failure patients. In this system, signs including electrocardiogram, $\mathrm{SpO}_{2}$, blood pressure, and weight are collected by non-invasive sensor nodes. These data will be transmitted from sensor nodes to a home sensor gateway for checking whether the status of a patient who is prone to suffering from heart failure is abnormal, compared with the pre-set safety value range. Once the detected values are beyond the threshold, alerts will be sent from home gateway and calls for instant supports, which allows earlier home interventions thus reducing the number of hospitalizations.

The Internet of Things also has significant impacts on the elderly who are living alone and their families by continuously tracking their health. When someone's daily activities are disturbed or changed, the alert mechanism will send signals to family members and medical personnel. For example, falls are a serious problem for the elderly, so it is imperative to apply falls detection in the daily life of the elderly. There have been plenty of IoT-based fall detection and alerting solutions. In Gutiérrez-Madroñal et al.'s (2019)solution of fall detection, once their motion sensors observe that the change in the acceleration of human motion conforms to the fall pattern, these sensor nodes will determine a fall event, and then an alert will be sent for help.

The combination of home monitoring devices, such as wearables and fog computing, can allow doctors to more effectively track the patient's health. After the sensors installed on the patient are processed locally, the data necessary for the doctor's diagnosis will be uploaded to the cloud. Doctors can track the patient's compliance with the treatment plan or any need for 
immediate medical attention. The Internet of Things has made healthcare professionals more alert and able to proactively contact patients. The data collected from IoT devices can help doctors determine the best treatment process for patients and achieve the expected results (Alam et al., 2018).

Internet of Things for hospitals. The National Health Service in England declared the practices of using IoT in healthcare is effective in tracking medical supplies and automating basic data collection and patient monitoring, so that the experienced healthcare workers can be set free from repetitive tasks to focus on patients' safety and services(Best, 2018). Hospitals can use IoT technology to track the use of medical equipment and consumables. In most hospitals, equipment such as electrocardiographs and analgesic pumps needs to be shared by patients. IoT can not only provide insights for hospital staff to plan resource allocation by sending the realtime location of the device, but also can be used to monitor the maintenance status of the device and issue alerts when appropriate. For some medical consumables that are being consumed at fast speed, low-cost RFID tags allow them to be marked, so it is easy to count usage and then charge the patient's account. At the same time, tracking the usage of these medical consumables can also help hospitals manage inventory. For example, when the consumption of certain items is too high or the rate of use is too fast, an alarm will be issued to remind the hospital to replenish inventory or reduce excessive consumption (Laplante \& Laplante, 2016).

For hospitals and some other healthcare providers, the significance of using IoT is that after collecting a massive amount of data from ground devices, meaningful trends and conclusions can be drawn through centralized sorting and analysis. These analytics deliverables can be suggestions of medical assistance or overall visualization of the condition of a patient group. Figure 1is an illustration of the workflow of IoT solutions in healthcare (Mora et al., 2017; Mora, Gil, Terol, Azorín, \& Szymanski, 2017) 


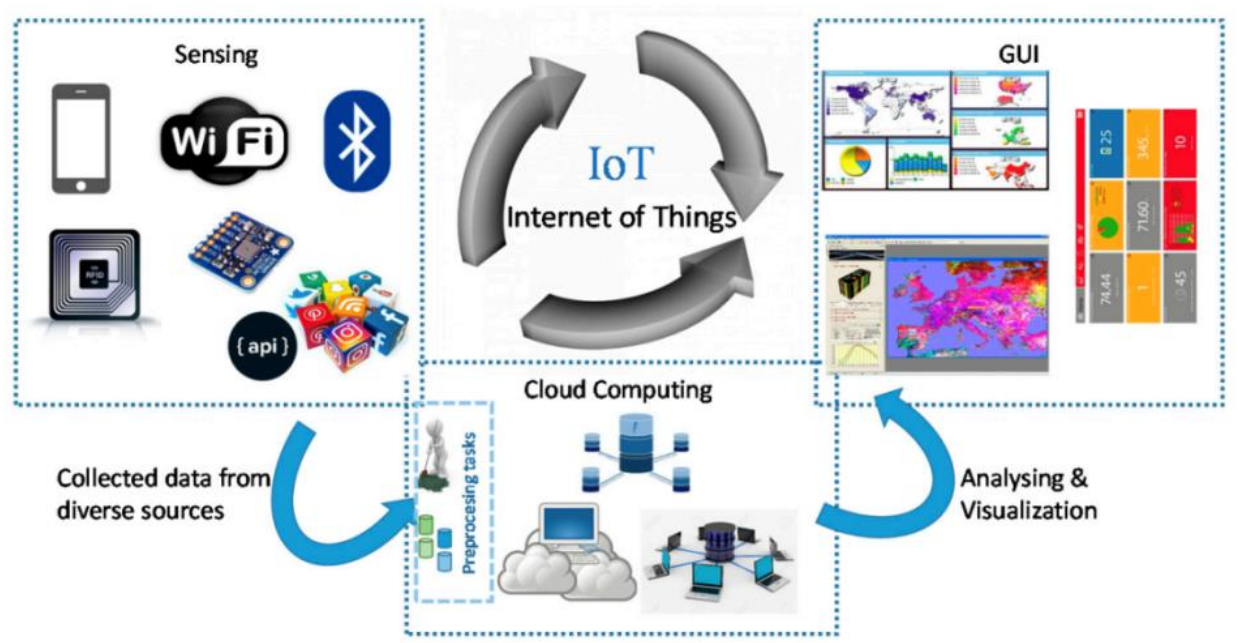

Figure 1. Schema of IoT workflow (Mora et al., 2017)

\subsubsection{The Internet of Things in Finance}

The applications of IoT have transformed the way that the financial sector works. Khanboubi et al. (2019)summarized the following trend in which IoT solutions are changing financial services, mobile banking, crowd-based financing, virtual money, high frequency trading firms, cyber criminality, big data and IT analytics. The applications of IoT in finance can be classified into two categories, one is financial services for individual users and corporate users, and the other is the measures used by banks and other financial institutions to optimize and upgrade their own workflow. The most common of the first type of application is the banking service provided to users that can be accessed at any time through a personal terminal. These services include using the user's biological information to perform security authentication of the banking business or to replace the physical signature during the business process; using the built-in near-field communication technologies (NFC) module of mobile phone or wearable device to complete contactless payment; collecting funding from a large number of individual to support a project financially via an online platform (Khanboubi et al., 2019).

There are some other IoT applications in finance designed for business security and risk management. For example, Industrial and Commercial Bank of China is using IoT solutions for its financing business risk management practices. RFID tags are deployed on collateral to detect the movement of objects. Any abnormal movement can trigger the alarm system, a realization 
of the automatic collection of alarm information and early warning of risk monitoring (InfoQ, 2019).

\subsection{Concerns regarding sensor nodes and the network}

As discussed above, ICT sensor networks can indeed play an effective role in detecting farmland environment and controlling the application of yield technology, but use of this technology in agriculture is confronted with the limitations and challenges including, but not limited to, lifetime, energy and reliability.

\subsubsection{Energy consumption and Battery life}

The power unit is an essential part of an ICT sensor node (Sliva, 2008). Rechargeable batteries are usually used for power supply in a sensor node, which have limited capacity and pose a challenge to long-term deployment. These batteries provide stable electricity to the other module in a sensor node, so that each part of the node can work properly. To enhance energy efficiency within a sensor node, the circuits and algorithm of the processing and calculating module of a node have to be further optimized (Jawad, Nordin, Gharghan, Jawad, \& Ismail, 2017). In wireless sensor networks, the lifetime of a node is generally determined by its power unit, usually the life of batteries used in the sensor nodes. To utilize the maximum of the battery life, power consumption of the nodes should be strictly controlled, which means that the program and algorithms inside the nodes should be optimized and improved (Sliva, 2008). The good news is that the problem of limited node lifespan can be addressed, with the use of energy-harvesting techniques. Numerous techniques have been developed to allow sensor nodes to harvest different types of energy, such as solar, wireless power transfer, mechanical vibration, kinetic, and wind energy, from different environments. Ambient energy can be converted into electrical energy, and the electric energy can be used to charge the battery of a sensor node, or it can be stored for later use. In agricultural applications, energy harvesting can be used to extend the life of sensor nodes (Jawad, Nordin, Gharghan, Jawad, \& Ismail, 2017).

\subsubsection{Equilibrium among energy consumption, transmission range and node performance}

In the realm of wireless communication protocols, ZigBee consumes much less power than these traditional transmission methods, including Wi-Fi and GPRS, but the latter has a wider transmission range. Similar trade-offs occur from time to time. Zigbee and low-energy 
Bluetooth are designed for battery-powered devices. Low-energy Bluetooth is superior to ZigBee in terms of power consumption, but due to its short communication distance of 10 meters, the protocol is limited in agricultural applications. The Long-Range Radio (LoRa) Protocol covers large communication areas with low power consumption. Therefore, it can be appropriately deployed in a wide agricultural field. However, for this protocol, limited communication time per hour for each device and message capacity for communication, and its dependency on gateway make this protocol no longer the best option for configuring agricultural ICT sensor networks (Jawad, Nordin, Gharghan, Jawad, \& Ismail, 2017).

\subsubsection{Transmission loss}

When deployed for agricultural purposes, WSN faces a more difficult environment than other uses, such as outdoor, orchards, farms and other complex terrain. Signal transmission will be disturbed by obstacles. In agricultural applications, signals transmitted from sensor nodes need to reach the receiving node through a thick canopy. If a sufficient gap cannot be ensured, the signal will be absorbed, reflected, attenuated and scattered during the propagation process (Jawad, Nordin, Gharghan, Jawad, \& Ismail, 2017).

\subsubsection{Immediate and reliable}

The starting point for the establishment of WSN determines that one of its first tasks is to provide farmers with low-latency environmental information. Most crops are easily affected by the weather. If WSN fails to detect environmental changes in a timely manner, or detects information but does not transmit it to relevant clients in a timely manner, it may lead to serious agricultural disasters, such as large-scale diseases and insect pests, floods, fires, etc. Regarding some existing ICT sensor networks deployed in farms, the way they work is still to wait until symptoms appear so that the disease can be detected. Such systems do not qualify as early warning systems in detecting disease and pests (Datir \& Wagh, 2014).

\subsubsection{Fault tolerance}

In ICT sensor networks, it is normal for one of the hundreds of thousands of nodes to fail. Common causes include power exhaustion, communication failure, and sensor module failure. At this time, the most important thing is to design a set of topological structures with strong fault tolerance, to prevent the entire network from collapsing due to a failed node(Jawad, 
Nordin, Gharghan, Jawad, \& Ismail, 2017). Apart from solving this problem from the perspective of network topology, some further improvement on the combination of nodes architecture and the network can be done as well. Geeta et al.(2013) suggested a possible way of improvement. A single sensor node should have the capability to send early alert to its neighbour node when its battery is low or when it gets external interference, offering the network with enough time to adjust a transmission route to avoid network collapse. Hang et al.(2015)designed a three-tiered unmanned aerial vehicle sensor network for capturing information from farmland. This architecture realizes the extension of the life of sensor nodes by reducing the transmission tasks of sensor nodes in WSN. It enhances the data collection efficiency and life of the entire system by enhancing the function of relay nodes and power supply, reducing resource consumption caused by transmission node failures, and improving the network communication quality provided by mobile nodes.

\subsubsection{Data management}

Agricultural monitoring practices generate large amounts of data because multiple WSNs in agricultural applications include multiple crop sensor growth analysis and harvest estimates. This situation requires the base station to monitor and change farmland through analysis mode. Therefore, base stations must support high levels of storage capacity (Jawad et al., 2017).

\subsection{Review of ICT sensor networks in agriculture}

Digital farming is the practice of modern technologies such as sensors, robotics, and data analysis for shifting from tedious operations to continuously automated processes (Shamshiri et al., 2018). The terms digital farming and precision agriculture are often used to describe the same concept in many current contexts, but they are not the same thing. The concept of precision agriculture (PA) has been proposed for ages. At the very beginning, PA was mainly focused on the matching of environmental factors such as insitu climate, soil property, and crop species (Krishna, 2016).

Innovation in digital farming occurs where the crops interact with their external environment, for example, the physical, biological, and chemical components (Es van \& Woodard, 2017). Therefore, inspiration for innovations could be derived from the factors that affect crop productivity. Lazarcik (1963) developed a term output-input ratio for measuring 
productivity. This ratio is about the relationship of agricultural output to all production inputs used to produce that output. It measures average aggregate productivity of all inputs together (operating expenses, depreciation, interest on capital and cost of labor). It indicates that in order to increase the productivity in agriculture, measures aiming for both higher output and smaller input should be taken.

There have been many achievements in using wireless sensor networks in farms to monitor the environmental factors that affect crop yield, including but not limited to soil moisture, temperature, $\mathrm{pH}$ value, soil microbes load. Kalaivani et al. (2011)surveyed ZigBeebased wireless sensor networks in agriculture, which covers the features and some drawbacks of the application of ZigBee in agribusiness. This transmission protocol has good capability of transmitting data with few losses within its complimentary range, with low power consumption, price and deployment difficulty. However, the transmission quality can be significantly impaired as the distance changes and vegetable canopy keeps growing. The reason is that there is a significant gray zone which is a range of distance between transmitter and receiver where the transmission doesn't work, and if the route between transmitter and receiver is physically blocked by plant canopy, the connection would be disturbed and closed (Kalaivani, Allirani, \& Priya, 2011).

Yadav et al. (2012)described a method to use wireless sensor networks to ensure that everyone has enough food in some developing areas. In this study, wireless sensor networks were used to monitor the life cycle of food from producing stage to sales stage. This monitoring process includes establishing a database by mapping agricultural production and food shortages, constructing efficient ways of communication during emergency, monitoring real-time agricultural conditions and sending an alert if an indicator meets its threshold.

Ojha et al.(2015)reviewed various applications of WSNs in an agricultural context. They divided wireless sensor networks into two types according to different scenarios, which are Terrestrial WSNs and Underground WSNs. They also listed some potential applications such as automated irrigation scheduling for saving water, maintaining an optimized environment for higher plant growth, monitoring cattle activities and ground water quality to ensure the cattle are staying in an appropriate environment and location, simulating greenhouse gas distribution, and agricultural production processing monitoring. These applications indicate 
the feasibility of utilizing ICT sensor network technologies in farms to improve production by creating optimal environment for crops.

Zhao et al. (2010) designed a greenhouse environment monitoring system using IoT technology. This system can control the on-site environment in real time according to the needs of plants for temperature and humidity. Also, it's able to collect a large amount of environmental data and send it to research institutions for further processing and analysis. Dholu and Ghodinde (2018)created a similar IoT-based system which can sense necessary parameters from the environment and make the necessary decisions to control an actuator for irrigation.

The application of the Internet of Things in agriculture is not limited to reading environmental parameters and then taking corresponding irrigation or fertilization measures. The information collected by smart devices in the Internet of Things can be accurately analyzed to improve agricultural productivity. Elijah et al.(2018)classified the analysis into the following categories.

Prediction. The huge quantity of environmental data such as moisture and temperature collected by sensor nodes and other smart devices in an IoT network can be used to develop predictive algorithms to notify when diseases, drought, flood or fire is about to happen.

Inventory management. In terms of storing agriproducts, external moisture and temperature can influence the quality of products significantly. In this scenario, sensor nodes are deployed in inventory to collect this information. After the data analysis has been sent to the cloud and analysis has been conducted, automatic command will be sent for adjusting the condition of inventory. This practice can reduce the negative influence of spoilage and pests on food quality.

Decision making. Big data obtained from sensors provides learning opportunities to improve decision-making for changing environmental conditions. An ideal outcome of this analysis is automatic decision-making by IoT systems involving few human interventions, which could set the workers free from repetitive work.

Insurance. Agricultural activities are vulnerable to natural disasters. IoT devices deployed in remote areas can notify farmers or insurance companies when a hazard or disaster 
is detected, reminding them to settle claims. When extreme weather or another condition is detected, access to information by an insurance company can allow the company to make automatic direct payment to policyholders, initiated by the IoT system (Elijah, Rahman, Orikumhi, Leow, \& Hindia, 2018).

Utilizing ICT sensor networks for collecting data from farmland assists the farmers to match cropping practices to climatic trends, to use inputs and resources more sustainably and reduce environmental impact, and to cope with productivity threats. Moreover, it can enable public officials to integrate the data across the country and to adjust policies to reflect the data collected, to predict food supplies, and to target social programs or promote yield technologies (World Bank, 2017).

3.6 How do crops interact with the external environment?

\subsubsection{Environmental factors}

\section{Water and temperature}

Unfavorable water and thermal conditions could sharply reduce crop yields. For example, excessively high temperature proved to have negative effect on the yield of maize (Carter et al., 2016) and at the same time low-temperature stress may damage photosynthesis (Oquist, 1983).Excessive high or low temperature would impede the activity of enzymes, and affect the efficiency of metabolism of plants.

Agriculture is one of the major consumer industries in the world (Cazadilla et al., 2010). Two aspects related to water consumption should be considered, the direct effects of water content on crop growth, and the economic cost of using water. In agribusiness, the term water

productivity (WP), defined as the amount of yield produced per unit volume of water $\left(\mathrm{kg} / \mathrm{m}^{3}\right)$, is often used to assess the efficiency of water usage (Patil et al., 2015). Therefore, higher yield with smaller water input can be regarded as success in improving the productivity of crops. Respiration by soil microorganisms can increase with increasing irrigation under water stress, but excessive irrigation can suppress soil respiration under the condition of flooding (Wang, Zhao, \& Ouyang, 2010). For the crops, changes in atmospheric moisture can alter the way their stomata work, and in turn the process of plant transpiration, energy balance and tissue temperatures (Grantz, 1990). In some cases, the combination of high temperature and high 
vapor pressure deficits could result in crops wilting when the water that crops take up from soil cannot make up for the evaporation loss into the air (Carter, Melkonian, Riha, \& Shaw, 2016).

\section{Soil nutrients}

Soil nutrients can be divided into three types according to the amount that plants need during for growth: primary nutrients, secondary nutrients and micro-nutrients (Moore \& Bradley, 2018). Fertilizer can be considered as a supplement to the original deficiencies in the soil, and the amount of fertilizers added to the soil should be precisely calculated and controlled. $\mathrm{N}, \mathrm{P}$, and $\mathrm{K}$ are the most limiting factors in crop production (primary nutrients) (Warpe \& Pippal, 2016).However, excessive application of N-P-K fertilizers would lead to degradation of both soil and water quality, and production of crops. For example, nitrate leaching from the irrigated farmland may move to lakes and groundwater, and then result in eutrophication in lakes and nitrogen pollution in groundwater (Ju et al., 2007; Savci, 2012). This practice in controlling the volume and usage of fertilizer is coined as fertilizer management, which takes environmental, agronomic and economic effects into consideration (Matson, Naylor, \& OrtizMonasterio, 1998).

\section{Soil $p H$}

A major issue regarding soil $\mathrm{pH}$ in agribusiness is soil acidity, resulting from diverse causes. For example, the parent rock material may enter soil or groundwater due to weathering $(\mathrm{Xu}, 2015)$. Another cause of acidification emerging in recent decades is the excessive use of chemical fertilizers. Common chemicals found in artificial fertilizers, including ammonium sulfate, ammonium phosphate, potassium nitrate, and ammonium nitrate have proven to be able to lead to increase in $\mathrm{H}^{+}$concentration in farmland soil (Pierre, 1928). A direct effect of higher concentration of $\mathrm{H}^{+}$on soil is that activities and metabolism of the microbes in soil could be affected. Altered soil $\mathrm{pH}$ may create conditions that are less optimal for microbes or plants. Extreme $\mathrm{pH}$ could even inactivate them. Some researchers have demonstrated the correlation between the soil enzyme activity and crop yield (Tautges, Sullivan, Reardon, \& Burke, 2016). There is another indirect effect that $\mathrm{H}^{+}$could have on the soil. Higher concentration of $\mathrm{H}^{+}$ could change the form in which aluminum (and other metals) exist in soil, and can increase the 
solubility of $\mathrm{Al}^{+3}$ in soil pore water (Gazey \& Azam, 2018). Excessive aluminum can lead to the death of aquatic organisms, the wilting of terrestrial plants, the reduction of crop yields, and the decline of forests (Weng, Huang, Liu, \& Sato, 2000). Research conducted by AbruñaRodríguezet al. (1982) showed that higher concentrations of $\mathrm{H}^{+}$and $\mathrm{Al}^{+3}$, decreased the yield of crops like yam and cassava relative to their maximum yield.

\section{Soil microbes}

Soil microbes consist of the fungi and bacteria in soil. Soil microbes maintain or alter the microscopic soil physical and chemical properties by their metabolic activities, including the soil properties in the plant rhizosphere, influencing the efficiency with which plants are able to utilize the soil nutrients (Sessitsch \& Mitter, 2015). There is increasing evidence that biotechnology using microbes or their metabolites can enhance nutrient uptake and yield of crops, control pests and reduce plant stress responses (Trivedi, Schenk, Wallenstein, \& Singh, 2017). At the same time, research conducted by Gu et al. (2009)showed that a combination N$\mathrm{P}-\mathrm{K}$ fertilizer could increase soil microbial biomass, diversify bacterial communities, and maintain crop production.

\section{Soil depth}

Research conducted by Khakural et al.(1996)shows that the fertility of deeper soil can contribute much to crop yield than the fertility of topsoil. Williams et al. (1999) found that under sub-optimal living conditions, the properties of topsoil are definitely important for predicting crop yield, while the properties of subsoil are relatively more important in limiting crop yields under normal conditions (Williams, Ahuja, Naney, Ross, \& Barnes, 1987).

\section{Farmland slope}

Farmland in sloping area tends to have a thinner layer of soil (Atherton, Morgan, Shearer, Stombaugh, \& Ward, 1999). Steep slopes are more vulnerable to soil erosion, therefore soil layer on the slope is usually thinner, and the soil water content and soil fertility are also relatively poor (Mohammadi, Jalali, Kooch, \& Said-Pullicino, 2016), although Yang et al.(1998)found that the slope of farmland can have a positively significant relationship with yield of wheat. 


\subsection{Cultural factors}

Common cultural practices in agriculture include irrigation patterns, fertilizer application, planting spacing and density, intensity of various routine agricultural practices, and harvesting time. The mechanism by which some of these practices is able to influence crop yield is by modifying the availability of sunlight (Atherton, Morgan, Shearer, Stombaugh, \& Ward, 1999). Pathiratna et al.(2004)conducted several experiments to study the effects of fertilizer, spacing and shade on the growth and yield of Aerva lanata. Results from these experiments showed that crops treated with organic and inorganic fertilizers could produce higher dry matter yields. Crops established with a closer spacing have lower yield and growth than those with wider planting spacing, if yield per area is not considered. Ashraf and Saeed (2006) compared two different irrigation methods in an area with saline groundwater. The result shows that root zone of the crops which are treated with alternative, reduced-frequency furrow irrigation has smaller accumulation of salt than that with regular furrow irrigation (Ashraf \& Saeed, 2006). The planting date of a crop is fundamental information for the modeling of planting activities. It can be calculated based on historical weather information (Dobor et al., 2016). Research conducted by Kucharik (2008) in the United States shows that the planting date, especially the timing of planting the seeds has a significant impact on yield of maize.

Apart from the factors above, Krebs (1984)mentioned that there are some major ways that crops yield can be improved, including (1) improved quality of crop varieties, (2) improved resistance to diseases, (3) improved resistance to insects, and (4) adaptation to climatic condition.

These known factors provide direction for researchers and farm operators to improve crops yield and labor productivity. Among these factors, soil properties that can be measured by sensors include soil moisture, concentration of specific ions required for plant growth, and soil electrical conductivity. Lab test and insitu measurements on these soil properties of their corresponding sensors are well matched. However, for a lot of soil nutrients and soil organic matter, there are not reliable sensors for measurement. 
3.8 Integration of sensor networks with other ICT products for boosting production in agriculture

Agriculture is an important sector for the continuous growth of developing countries, especially large agricultural countries. More than $80 \%$ of those who live in remote areas are engaged in agriculture. The World Bank provided a guideline to guarantee the security of reliable and stable access to nutritious, affordable food, with access resilient to climate change. As the World Bank pointed out in a report, increasing the output of the agriculture, forestry, animal husbandry and fishery industries requires: 1) utilizing insitu technologies to characterize field conditions, in order to provide the optimal resources for plant growth. These farming practices, after optimization, would result in more sustainable and profitable farming; 2) eliminating yield losses through early warning systems. This revolves around identifying the infection, disease, and upcoming bad weather.

Most farmers have access to the means of production and yield enhancing technologies that can help them increase their crop yields, such as fertilizers and pesticides. Meanwhile, sometimes they do not know how to use these products in a proper way. Although these products are usually equipped with instructions, different application scenarios always have different applicable standards, with no universal standard practice. In this case, ICT technology can fill the gap of farmers' knowledge. With the help of ICT farmers can use the optimal solution for consuming resources in agriculture(World Bank, 2017).

In agricultural production, unmanned aerial vehicles (UAV) are often used in conjunction with ICT sensor networks. UAV is very suitable for spraying pesticides and fertilizers due to its high speed and spraying efficiency (Costa et al., 2012). However, as is mentioned in Faiçal et al.'s work(2014), the working route of a UAV spraying pesticides or fertilizer is prone to being disturbed by wind.The architecture and workflow of Costa's $\mathrm{UAV}+$ sensor networks monitoring system was similar to that of Faiçal et al. The UAV has to communicate with sensor nodes on the ground periodically to make sure that it's in the proper location (Costa et al., 2012).

Zhang et al. (2015) designed a three-tiered UAV farmland sensor network (TUFSN) for capturing information. Figure 2 is an illustration of their network architecture. The data collection layer on the ground is where the distributed sensor network can monitor the external 
environment and grab information. In this layer, a large number of sensor nodes are deployed to strengthen the monitoring of a target data collecting area. Another feature of this layer is selforganization. Layered protocols and distributed algorithms allow wireless sensor nodes to autonomously schedule their work processes. When deployed to a specific area and activated, the corresponding network can be organized automatically. The relay transmission layer consists of a network established between the relay node and the UAV mobile node. This layer has the following characteristics: 1) simple structure: direct communication between UAV and the data collection layer; 2) more energy available: the data collection layer is generally powered by solar energy so that UAV can be powered by rechargeable batteries; 3) stable and reliable: UAV communicates with the ground data collection layer in the air. The possibility of being blocked by plants or houses in the middle is low, and the packet loss rate will be reduced; 4) Long communication distance: the communication quality is good, and it can provide larger power antenna coverage. The mobile convergence layer consists of a single or multiple UAVs and a network established between data centres. UAV and data centres are directly connected by a cellular data network. The mobile convergence layer network has a very long communication distance, has error detection and packet loss retransmission functions, and supports real-time or delayed data transmission. Compared with the traditional static WSN, in terms of economic efficiency, this architecture is more suitable for scattered land, hills and mountains, and the ground wireless sensor network has difficulty or is unable to form a complete network due to natural environment constraints. They are divided into multiple independent networks. The limitation of this system is that flight missions are performed only when data are needed, so the frequency of UAV flights determines the frequency of data updates (Zhang et al., 2015). 


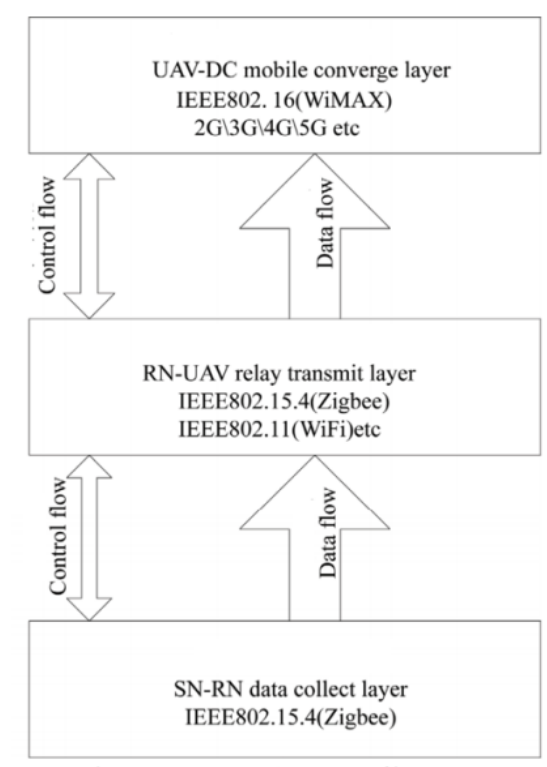

Figure 2. Three-tiered UAV farmland sensor network by Zhang et al. (2015)

Apart from the sensor networks studied in this article, image-based techniques are another major part of the ICT solutions applied in agriculture. Remote sensing is a hit. In general, remote sensing technology refers to acquiring image information about an object in a non-invasive way, without actually coming into contact with it, from a physically high altitude and a macro perspective (Horning, 2008).

When applied to agriculture, the major role of remote sensing technology is to collect raw data from farmland. The methods of obtaining data and the form of data from mobile phones include aerial images taken by airplane, helicopter, radio-controlled aircraft, and unmanned aerial vehicles; satellite images captured by satellites in orbit; surface GPS receivers and satellite linkage to obtain positioning information; laser scanning, using a set of laser beams to measure accurate elevation, i.e. the distance from an aircraft to features on the ground, pruning the disturbance of trees and buildings on the ground. This means that when measuring the elevation of sensing aircraft, ground elevation under tree canopy can be measured (World Bank, 2017).After data are collected by remote sensing technology, the following analytic tools are used to provide a deeper understanding of the farmland system being studied. With spatial modeling, existing data can be used to simulate the real-world farmland. Using data mining techniques, patterns of crops, such as their growth rate characteristics can be extracted from the data set. 
The workflow of collecting and analysing image-based data has been widely used in agriculture. Reinecke and Prinsloo(2017)designed a system, using drones to capture aerial photos of plant leaf. These data were used to determine whether the crops were healthy. Honkavaara et al.(2013)used drones to take aerial images at pre-set time intervals at the beginning of the crop growing season, during the season, and before harvest to check the growth of the entire field and highlight growth stagnation caused by insufficient irrigation or low initial nitrogen content. Biossard et al. (2008)provided a technique based on automatic interpretation applied to images of rose leaves scanned in situ. They propose a cognitive vision system that combines image processing, learning, and knowledge-based technologies. The system is able to detect and count white flies (Trialeurode Vaporariorum Westwood) at maturity. This technology provides early warning for pest management so that measures can be taken to reduce losses before the pests become severe.

Application of remote sensing technology is not limited to identifying bad weather, plant disease and pests. On a smaller scale, this technology is widely used on individual crops, such as for classification of vegetables, fruits, and livestock. Traditionally, the classification work is often finished by the human workers who are well trained and experienced. However, there are some disadvantages to relying on the human workforce for classification. For example, the classifying worker may feel tired or lose concentration and then lower the accuracy of classification. Ideally, there should be a standard diagram for the workers to refer to when classifying, which will increase difficulty of work. Also, raters are prone to various illusions (Barbedo, 2013). Therefore, image processing techniques are needed for these tasks to relieve workload.

Gastelum-Barrios et al.(2011)reviewed newly emergent non-invasive image processing methods in determining the quality of fruits during and after the harvesting period, and concluded that it is a high-efficiency and harmless solution to grade the fruits. Singh et al. (2011)customized an automated classifier of four different bamboo species based on shape features of bamboo Culm sheath, using the central moment classifier. Their classifier for bamboo shows considerable recognition accuracy, which has great potential on saving labour of manually recognizing bamboo species. This outcome proved the possibility of putting this technology into commercial use. Latha et al.(2014) implemented an image processing function 
to detect weed areas. Once the function was equipped onto pesticide sprayers, the automatic sprayers can target these blocks covered by weed. This not only saves pesticides, but also avoids generating agricultural waste, and additional effects on the environment and other plants caused by excessive use.

Patil (2011) designed a measuring method for leaf area based on image processing techniques. A traditional graphic measuring method was used to verify the accuracy of measuring leaf area using image processing. The new method proved to have high precision and accuracy and take less processing time. This result provided a theoretical basis for the development of an imagery leaf area meter that meets the requirements of precision farming.

$\mathrm{Xu}$ et al. (2011)developed an algorithm that can tell whether the plants are suffering from nutrient deficiency, by recognizing the color and texture of the leaf. The accuracy of this diagnostic algorithm was above $82.5 \%$ and it was able to diagnose disease 6-10 days before experts could determine it. Arakeri et al. (2015)implemented a system which provided early warning to detect diseases on tomatoes. Tomatoes are very prone to a disease called late blight, which happens when leaves get infected with Phytophthora infestans fungus. Typical symptoms of fungus infection include irregularly shaped leaves and water-soaked lesions. This alert system was able to recognize whether a leaf was ill or healthy, and whether the leaf had contracted the Phytophthora infestans fungus. The accuracy of analyzing the late blight disease was $84 \%$. Chen et al. (2014)proposed an effective method for judging the nutrient content of crops. They extracted characteristic parameters from years of images of healthy leaves and nutritionally deficient leaves. They were able to determine from an image of a rice leaf whether the plant was deficient in N, P, and $\mathrm{K}$ based on the attributes of leaf sheath length, leaf area / leaf length, leaf tip, leaf lightness, etc. The average identification accuracy of this method for assessing N/P/K deficiencies was around 88\%.In 2019, Chen et al. optimized the algorithm of this detection method, and the average accuracy of recognition increased to $93.4 \%$.

Application of image-based technologies is not limited to crop assessment; it is applicable in animal husbandry as well. Image processing systems have been widely used in monitoring livestock for many applications, including identification, tracking, behavior analysis, occupancy rates, and activity calculations. Kashiha et al. (2014)designed an image processing system for checking whether hens were staying inside the chambers. This system could save 
much time on manually analysing videos for monitoring hen chambers. Pradana et al. (2016)designed a method to accurately estimate the weight of cattle, by visually measuring the body length, chest circumstance, height and width. Wongsriworaphon et al. (2012)conducted similar research, but their focus was to recognize individual pigs based on their size and weight.

Appendix Table A2 from Gong (2010) compares the differences of the node sensors from the perspective of price, reliability, performance and power consumption. This table also lists some environmental parameters that can be measured by available sensors, such as temperature, carbon dioxide concentration, and relative humidity.

3.9 A case study illustrating use of UAV and ICT sensor networks in sustainable agriculture

The system Faiçal et al. (2014)designed for the linkage of unmanned aerial vehicles (UAV) and ICT sensor networks for spraying pesticides is a typical application in agriculture, and is described in detail in subsections below to illustrate the use.

\subsubsection{Research background}

Spraying pesticides and fertilizers in farmland is vital for crop yields. Aircrafts are becoming more common and popular for this task, mainly because of the speed and efficiency of aircraft spray operations. However, certain factors may reduce yield and even cause damage. For example, the spraying process might miss some crop areas, repeat spraying in the same crop area, and apply pesticides to the outer edges of the farmland. This study proposed an architecture based on unmanned aerial vehicles that could be employed to implement a control loop for agricultural applications with UAVs responsible for spraying chemicals on crops. An algorithm to adjust the UAV's motion routes when confronted with constantly changing wind was also assessed in this work.

\subsubsection{Methods and procedure}

In this solution, an unmanned aerial vehicle and several sensor nodes are deployed in the farmland. The function of the sensor mainly includes obtaining the current concentration of the pesticide chemical from the soil. Sensor nodes also communicate with the drone in the air at any time to help the UAV verify its real-time position to avoid crossing a boundary and spraying where it should not, or spraying an area repeatedly, resulting in excessively high 
concentrations of pesticides in a small area causing damage to the crop. If the sensor detects excess chemicals, the drone in the air will be directed away from this area of excessive concentration. The role of the drone is relatively simple, it receives the concentration information on the ground and judges whether it is necessary to spray.

The researchers used the following steps to ensure that UAV sprayed pesticides where appropriate. (1) The algorithm sends a message periodically to query sensor nodes scattered throughout the farmland. A sensor node located at a previous location of the drone responds to this message with information about the amount of pesticide. (2) With this information, the drone can calculate the difference in pesticide concentration between each sensor node. (3) If the difference is larger than the predetermined threshold, the algorithm will re-plan the route, otherwise it will continue to advance in the predefined path and wait for the next round of query. Regarding the robustness of this proposed algorithm for spraying pesticides, the following aspects were assessed.

Calibration of UAV routes. An unmanned aerial vehicle is influenced by wind when it is working. A dataset containing information about wind direction and intensity was used to reproduce the constantly changing weather conditions, and check if the UAV was able to handle the changes. Also, considering the nature of the linkage of ICT sensor network and UAV in this project, whether the number of message exchanges between the two terminals would improve performance was evaluated.

Mapping the pesticide concentration. ICT sensor networks provide location information and information on chemical concentrations to the UAV. However, in practice, crops may not get the appropriate amount of pesticide. Possible reasons are the UAV may be flying too fast, or the pesticide spraying process may be disturbed by wind. Therefore, given the information about nodes location and their corresponding chemical concentration, a complete map of pesticide concentration distribution can be drawn. A heat map is an illustration of pesticide distribution, where green represents higher concentrations, and red low concentrations (Figure 3). For the spraying system in this study, an ideal outcome is that each node of it has the same or similar color. 


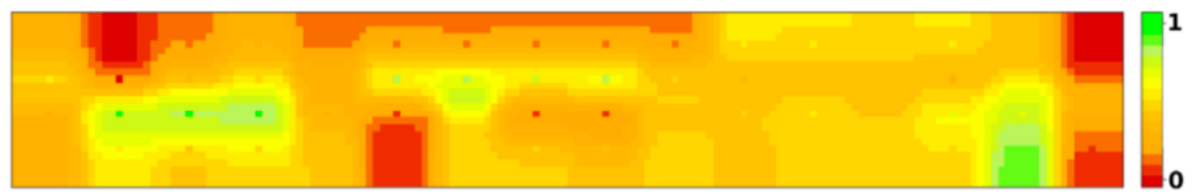

Figure 3. Map after the application of the interpolation technique (Faiçal et al., 2014)

Potential correlation between UAV height and spray coverage. Researchers speculate that drones need to fly to a certain altitude when spraying to get the best spray effect. There may be a relationship between the spray angle / coverage and the height of the drone, meaning that the higher the UAV's altitude, the larger the area covered by the spray may be.

\subsubsection{Case study results}

Figure 4is a map of pesticide concentrations after actual testing. Higher uniform the colors of this map represents higher stability and robustness of the algorithm, and this feature lets the vehicle to be more resistant to wind disturbance. Most areas of the farmland were sprayed with similar concentrations of pesticides, leaving only several small clusters with insufficient pesticide concentrations. Researchers assessed the relationship between time required for communicating with sensor nodes on the ground and height of the UAV, and the correlation turned out to be insignificant.

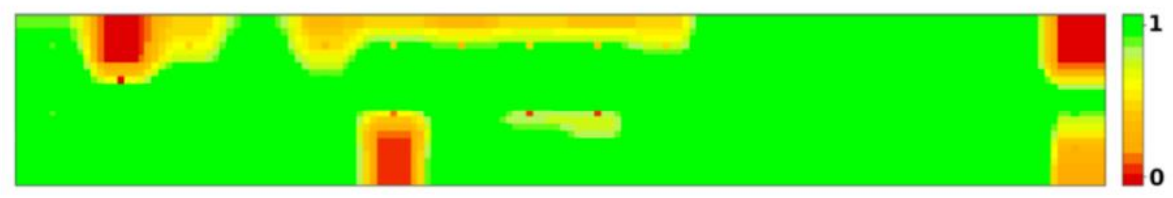

Figure 4. Map after the application of the threshold value (Faiçal et al., 2014)

\subsubsection{Case study summary}

This project provided a practical example of the combination of ICT sensor networks and some other ICT solutions, aiming to make agricultural activities to be more precise. According to the result of assessing with simulation tools, the algorithm designed for the collaboration between UAV and ICT sensor networks proved to work well. After further insitu testing procedures, it would be possible to utilize the system to improve sustainability in crop production (Faiçal et al., 2014). 


\section{Methodology}

This study consists of two parts designed to answer the research questions. The first part is to simulate the performance (which is indicated by annual yield in this study) of a farm where ICT sensor networks are deployed. The second part is to conduct a meta-analysis on the outcomes of existing studies and publications.

\subsection{Data sources}

Data and information for this study were collected by two major means, (1) published academic papers that discussed the change in crop yield of specific ICT sensor networks-based farms; and (2) contacting the companies who provide ICT sensor networks solutions for details of how the solutions they provide work and performance data of their service.

\subsubsection{Samples overview}

This study examines how the annual crop yield would change, when ICT sensor networks are deployed to control usage of water, fertilizer, and pesticide. Therefore, the sample farms in this study all use ICT sensor networks to control one or more of these agricultural resource usages. Figure shows the distribution of where the selected farms are located. The involved crop types in this study include maize, grape, rice.

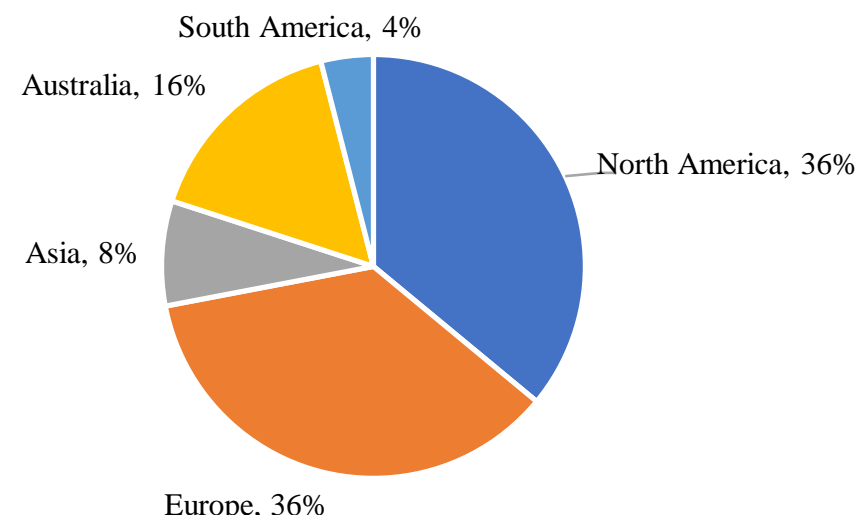

Figure 5. Geographical distribution of the farms involved

Yara Water Solution is a part of a Farm Management System offered by Yara Inc.in Norway, which can enable the farmers to save irrigation water. This solution provides a continuous and non-destructive way of measuring plant status. It uses sensors to measure the 
turgor pressure of the plants' leaves to determine if plants are deficient in water, and then makes a decision on whether to irrigate. The service provider of Yara Water Solution claims that with this solution, the irrigation water consumption would drop by $20 \%$ while yield increases by $15 \%$. Also, this solution will help save maintenance work and corresponding energy consumed (Yara, 2018).

Atfarm (2018) monitors the growth of fields with images taken remotely from satellite. It makes it possible for users to compare with images from previous years and to benchmark the development of crops. Its performance of saving resources and boosting crop yield is similar to Yara (Atfarm, 2018).

Accenture has been providing digital-based farm services to farm owners for years. These services are helping to improve financial performance and to boost yield. Accenture Digital Agriculture Services can help both large and small farms use digital technology to improve processes, increase yields and increase profitability to meet growing global food demand and to reduce the overall environmental impact of agriculture. Digital Agriculture Service can help increase overall profitability by $\$ 55$ to $\$ 110$ per acre (Accenture, 2017).

The Field Manager created by Xarvio digital farming solutions supports the users to know better about the farmland they are working. The Manager can provide real-time information of water and nutrition and can generate a map for better visualization. Spray Timer is a product of the Field Manager scheme. As is stated on the official website, Spray Timer can save the amount of pesticide application by up to 30\% (Xarvio Digital FArming Solutions, 2020).

DSS4Ag is an expert system for precision farming research. This system uses advanced artificial intelligence and computer science technology to make spatially variable fertilizer use and economically optimal decisions for specific locations. Field testing was conducted in a wheat farmland, and the result showed a 39.7\% cost saving using the DSS4Ag as compared to those blocks managed by the farm's traditional uniform applications practices, with only a 3.3\% decrease in yield (Hoskinson, Hess, \& Fink, 1999).

Whiteley implemented a precision farming technology to monitor and control pesticide application. The research found that the estimated saving on pesticide can be as much as $80 \%$ of the original application (Whiteley, 2002). 
A closed-loop, distributed control and data acquisition system for site-specific irrigation management was introduced and developed by Wang \& Li (2013). The system is formed by a group of stationary field sensing nodes deployed in a field and a group of nodes, called P2K nodes. These nodes collected the data from the field and the central pivot system and transmitted them to a master controller through a power-line carrier communication. The system performance was compared with a conventional uniform irrigation treatment in a potato field. Results showed that, with essentially equal water consumption, the tuber yield under sitespecific irrigation management was significantly greater, by about $4 \%$, than the yield from uniform irrigation (Wang \& Li, 2013).

Bongiovanni and Lowenberg-DeBoer (2004)summarized the research carried out by Weisz et al.(1996)regarding the performance of ICT sensor networks in controlling the amount of pesticide applied in a commercial potato farmland. With the site-specific pest management program, the input amount of pesticide in this experimental area dropped by up to $40 \%$.

Bausch and Delgado (2003)built an application to figure out if it is feasible to use ground-based sensing and the N Reflectance Index to improve in-season N management of corn in a commercial sprinkler-irrigated field. The results indicated that the application could reduce the consumption of nitrogen fertilizer by $47 \%$.

In much of the literature that discusses ICT sensor networks in farms, the effects of using this service have not been clearly described. To describe the performance of this type of farm and the benefits of wireless sensor networks, two indicators should be provided - the percentage of agricultural resources that can be saved (e.g. water, fertilizer, or pesticide), and the effect on crop yield. Some of the articles reviewed reported both indicators, while some of them only provided one or neither of these indicators.

\subsection{Simulation}

In this study, one of the aims was to investigate the possible response to the equipment of ICT sensor networks in farms for controlling the consumption of means of production in agriculture. Before this predictive what-if analysis begins, the raw data collected from publications and service providers have to be cleaned and formatted well according to the methodologies in the following paragraph. 
The collected data are about the amount and percentage that usage of agricultural resources including irrigation water, fertilizer and pesticide can be saved and reduced by the wireless sensor networks solution in farm, and the amount and percentage that crop yield can be improved with the solutions. Apart from the numeric data, location and crop type are recorded as well. These two attributes are regarded as independent factors on sensor network performance.

The first step of data cleaning is to normalize all the raw data into the same value range, and at the same time keeping the original relative deviation. In this case, all the extents of change in crop yield and resource usage are converted to a value of percentage, which is the "final state" after ICT sensor networks interfering with the crop production activities. These normalized variables include incremental changes in crop yield with ICT sensor networks, percentage of saved resources, location, crop type, and information source. Table 1 is an illustration of the details that will be analysed.

Table 1. Illustration of raw data

\begin{tabular}{cccccc}
\hline$\cdot \begin{array}{c}\text { Percentage } \\
\text { that yields } \\
\text { increase to }\end{array}$ & $\begin{array}{c}\text { Percentage that } \\
\text { water usage } \\
\text { decrease to }\end{array}$ & $\begin{array}{c}\text { Percentage that } \\
\text { fertilizer usage } \\
\text { decrease to }\end{array}$ & $\begin{array}{c}\text { Percentage that } \\
\text { fertilizer usage } \\
\text { decrease to }\end{array}$ & Farm location \\
\hline 1 & 115 & 80 & 86 & 80 & Spain \\
2 & 103 & 61 & Colorado, US \\
\hline
\end{tabular}

Table 2. Data collected from publications. The missing values estimated by missForest are underlined. (link)

\begin{tabular}{lccccc}
\hline Service provider & Yield (\%) & Water $(\%)$ & Fertilizer $(\%)$ & Pesticide (\%) & Continent \\
\hline Yara & 115 & 80 & 86 & $\underline{75.12705}$ & EU \\
Atfarm & 115 & 62 & 69.69302 & $\underline{75.12705}$ & EU \\
Accenture & 120 & 48.01476 & 69.69302 & 36.63897 & NA \\
Xarvio & 106.0094 & 62 & 52.27461 & 85 & EU \\
Capgemini & $\underline{120}$ & $\underline{48.01476}$ & $\underline{69.69302}$ & $\underline{36.63897}$ & EU \\
Iteris & $\underline{120}$ & $\underline{48.01476}$ & $\underline{69.69302}$ & $\underline{36.63897}$ & NA \\
Bayer & $\underline{15.5508}$ & 60 & 69.69302 & 60 & SA \\
irrigNET & 130 & $\underline{56.91037}$ & 69.69302 & 50.7575 & EU \\
Trapnet & 110 & $\underline{62}$ & 66.70255 & 90 & EU
\end{tabular}




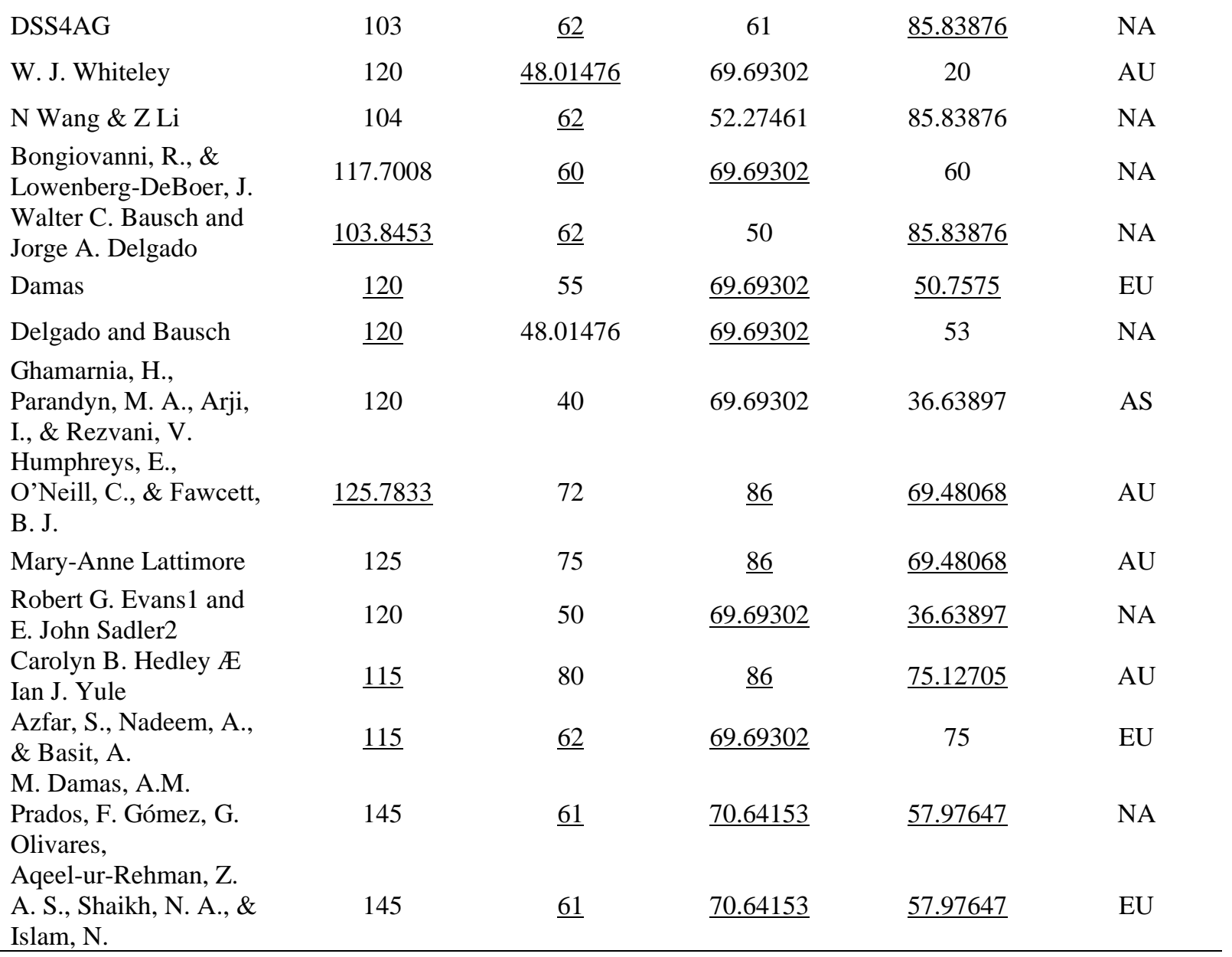

As is shown in Table 2, for some samples, one or more columns are missing. For this issue, a R package called missForest is used for filling the missing values. This package can handle multivariate data consisting of continuous and categorical variables simultaneously. This feature matches the variable type of the dataset in this study. Also, when applying this algorithm, there is no need in setting tuning parameters or making assumptions in data distribution. The full potential of missForest is deployed when the data include complex interactions or non-linear relations between variables of unequal scales and different types (Stekhoven \& Bühlmann, 2012).In other words, in contrast to the traditional way of using average or median values of missing data missForest uses a predictive algorithm based on a random forest trained on the observed values to predict the missing values. This will increase the accuracy of estimated missing values. So far, all the data used from here has been filled 
with missing values with missForest, and all variables have been normalized to the same value range.

For the modeling process, as is proposed in the methodology chapter, the first step of modeling was to preclude the statistical influence of locations on the performance of ICT sensor networks. For this analysis, the General Linear Model (GLM) Univariate procedure, which is based on the General Linear Model procedure, was used for testing the significance of the correlation of crop production increasing and where the farms equipped with ICT sensor networks are located. To assess the impact of location, general linear regression was run with the fixed factors being set as location. If the test statistic is outside of the confidence intervals, then the factor has a significant effect on the response variable. In this study, the statistical significance of the correlation between location and ICT sensor networks performance can be assessed by this test. The statistical software used for this step was SPSS. In the GLM regression setting in SPSS, the increased percentage of yield was set as the dependent variable, and the percentage of water/fertilizer/pesticide saved by ICT sensor network-based farms were set as covariates. This means that the change in crop yield is the result of combined changes in usage of agricultural input, controlled by ICT sensor networks.

The following central issue is to fit a function based on collected data. In this step, random forest was used as the basis model for simulating how the farmland would respond with ICT sensor networks equipped on site. Random forest is a classifier consisting of a collection of tree-structured classifiers $\left\{h\left(x, \Theta_{k}\right), k=1, \ldots\right\}$ where the $\left\{\Theta_{k}\right\}$ are independent identically distributed random vectors and each tree casts a unit vote for the most popular class at input $x$. When it comes to continuous numeric values instead of classification questions, the random forest model works as well. Random forests for regression are formed by growing trees depending on a random vector $\Theta$ such that the tree predictor $h(x, \Theta)$ takes on numerical values as opposed to class labels (Breiman, 2001). This regressor fits classifying decision trees on various sub-samples of the dataset and uses averaging to improve the predictive accuracy and control over-fitting (Pedregosa et al., 2011).

In terms of implementation of this simulation, a Python package called Scikit-learn was used. Scikit-learn provides a functional implementation of the random forest regressor model, RandomForestRegressor, which is written in Python. To optimize the accuracy of modeling, 
parameters including, but not limited to, the number of decision trees, maximum depth, minimum number of samples required to be at a leaf node can be set to the model instance (scikit-learn, 2019). This implementation has a class method score, which calculates the

coefficient of value $\left(1-\frac{u}{v}\right)$, where $u$ is the residual sum of squares of the difference between real value and predicted value, and $v$ is the total sum of squares of the difference (Pedregosa et al., 2011).

This model can be simplified to the form of $y=f\left(x_{1}, x_{2}, x_{3}\right)$, where $y$ stands for the increased percentage of crop yield, compared with the years during which ICT sensor networks are not used; and $x_{1}, x_{2}, x_{3}$ represent the percentage of saving on water, fertilizer and pesticide respectively. The selected random forest Python package provides several optional parameters, such as the number of trees in the forest, criteria to measure the quality of splitting a tree, and minimum number of samples required to be at a leaf node. I selected several parameters that have a significant impact on the random forest to fit the equation mentioned above, and then find a group of parameters that scored the highest among all the parameter sets in an iterative way. After 500 experiments, it was found that for the dataset in this study, the following parameter combinations had the highest scores, with a score of 0.9946 (out of 1). This score indicates that the current model fits the nature and distribution feature of dataset well.

$$
\begin{aligned}
& \{\text { 'bootstrap': True, 'criterion': 'mse', 'max_depth': None, 'max_features': 'auto', } \\
& \text { 'max_leaf_nodes': None, 'min_impurity_decrease': 0.0, 'min_impurity_split': } \\
& \text { None, 'min_samples_leaf': } 1, \text { 'min_samples_split': } 2 \text {, } \\
& \text { 'min_weight_fraction_leaf': 0.0, 'n_estimators': 1, 'n_jobs': 1, 'oob_score': } \\
& \text { False, 'random_state': 50,'verbose': 0, 'warm_start': False\} }
\end{aligned}
$$

Given a model that has been fitted, predictive analysis on the potential increase in crop yield with ICT sensor network deployed for controlling external environment can be conducted. With this predictive model, as long as the percentages of the three resources saved are input, we can get a percentage of how the crop output will change in a farm using ICT sensor networks.

\subsection{Meta-analysis}

Meta-analysis is a research method that summarizes, integrates, and interprets selected sets of scholarly works in the various disciplines (Lipsey \& Wilson, 2001).Glass (1976)defined 
this research method as statistical analysis on a collection of research results from individual studies. It is the application of specific design and statistical methods to the overall and systematic qualitative and quantitative analysis of previous research results. It is retrospective and observational, it is improvement on the traditional review (Xia, 2005).

Research findings which are applicable for this method must meet the following criteria: (1) they must deal with the same constructs and relationships, (2) they must be configured in similar statistical forms. To be specific, the involved studies must focus on the same correlation or causality relationship in the research scope. In meta-analysis, effect sizes are used to represent the outcome of each study. The effect size indicates the critical quantitative information from each study. It should represent either the direction or the magnitude of quantitative research findings, or both(Lipsey \& Wilson, 2001).

\subsubsection{Analysis steps}

The statistic tool used for the meta-analysis is an $\mathrm{R}$ package called metafor. The function $r m a()$ in this package allows for fitting fixed- and random/mixed-effects models with or without moderators via the usual mechanics of the general linear (mixed-effects) model (Viechtbauer, 2010).

There are two major models to use for meta-analysis, the fixed-effects model and the random-effects model. The difference between these two models is that a random-effects model allows the true effect to vary among studies. For further scalability (Brockwell \& Gordon, 2001), the random-effects model is chosen for this study.Then, the individual effect size foreach sample (i.e. finding) is calculated, using the calculating tools provided by Wilson(2001). The most common format of calculating effect size is $d=\left(X_{e}-X_{c}\right) / S$, where $X_{e}$ is the average value of an experimental group, $X_{c}$ is average value of the control or reference group, and $S$ is the common standard deviation of both groups(Peng \& Zheng, 1999). The value of the overall effect size is positively related to the influence, which means that higher effect size indicates greater influences (Yuan, Sun, You, Liu, \& Li, 2018).

In this study, standard deviation from the involved studies is collected for further analysis. For these publications that did not provide the statistical information, emails for enquiry were sent to the authors. 


\section{Results and Discussion}

\subsection{Research question evaluation}

Research question 1: To what degree can ICT sensor networks boost crop yield by monitoring and controlling the usage of water, fertilizer, and pesticide?

According to the result for the test of between-subjects effects proposed in Section 3.2, the significance value for location (continent) term is $0.181(\mathrm{p}=0.181$ ), which is higher than 0.05 . Table 3 is the result of statistical analysis from SPSS. Therefore, the correlation between increased crop yield and continent was not statistically significant. From a statistical point of view, the influence of area on performance can be temporarily excluded in this study.

Table 3. Result of Test of between-subjects effects from SPSS

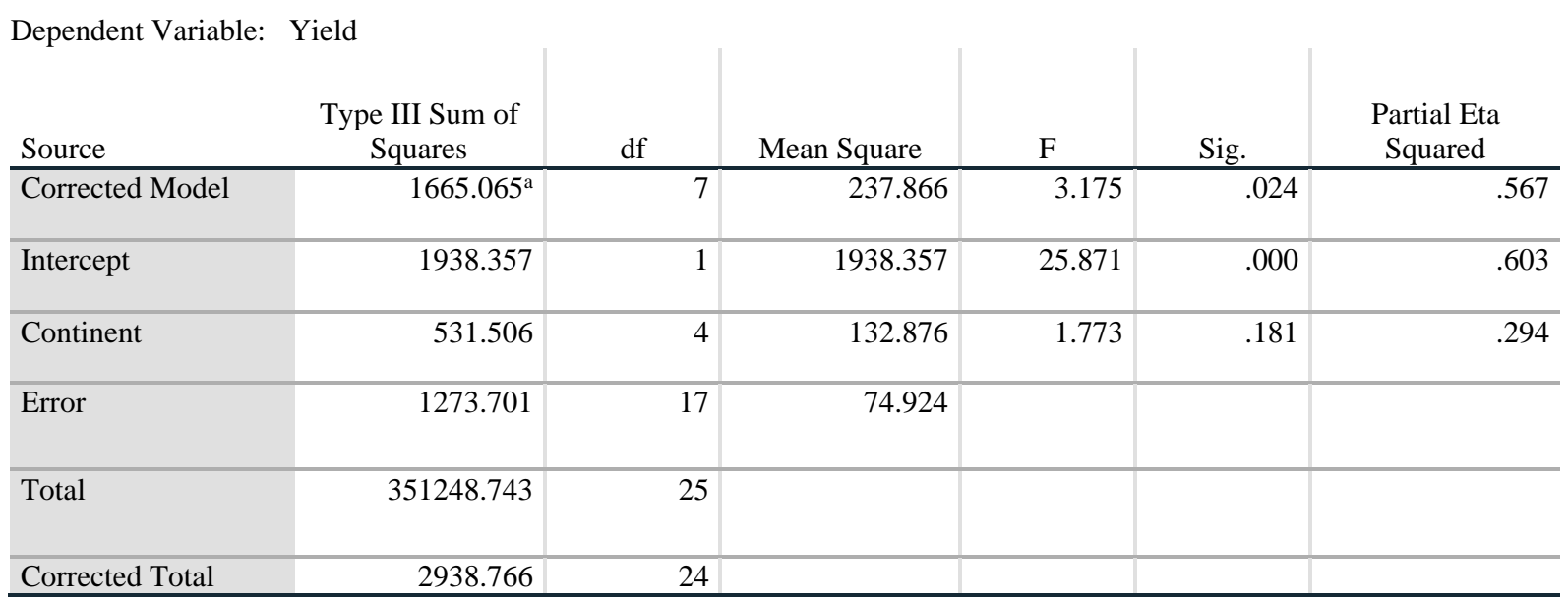

For the collected samples of farms equipped with ICT sensor networks, their normalized changes in percentage of consumption of irrigation water, fertilizer and pesticide are $80 \%, 86 \%$, and $75 \%$ respectively, compared with the conditions that these ICT solutions were not utilized on site.

Given the random forest model built above, a percentage to which the ICT sensor networks can assist farms increase yield can be estimated. In this case, with the predict() function provided by RandomForestRegressor class in Scikit-learn, prediction based on the model that was fitted, with parameters as the above three percentage value set $(80,86,75)$ can be conducted. Output value of this prediction turned out to be 116.26746667 . This result 
indicates that, if the ICT sensor network can be deployed and used in a crop farmland, with an average percentage of saving water, fertilizer and pesticide resources, the corresponding estimated increase in crop yield is approximately $16 \%$.

According to the results of simulation, the deployment of such ICT sensor networks on farms can indeed reduce the amount of agricultural resources (such as water and fertilizers) while increasing crop yields. Such a decrease in input and an increase or change in output just improve the productivity of the farm, which is in line with the idea of sustainable development in agriculture. In addition to increasing production, the more important significance of this application is to reduce the impact of human agricultural production on the natural environment by controlling the amount of chemical substances used. This protects animals and plants from toxic chemicals on the one hand, and protects human safety on the other.

Research question 2: If ICT sensor networks could be deployed throughout a selected country/area, how could the annual yield of crops change?

For this research question, Canada is taken as an example for estimating the potential in increasing crop yield with ICT sensor networks. Except for 2015, in the past five years, Canada's annual principal crop yield has remained at around 88.6 million metric tonnes (Statistics Canada, 2020).At the same time, according to previous research results, the consumption of irrigation, fertilization and spraying of pesticides on those farms using ICT can be reduced to $80 \%, 86 \%$ and $75 \%$ respectively, with boost of annual crop yield by $16 \%$.

If the result of this estimation is extended to the entire scope of Canada, taking into account the average crop yield of Canada over the past five years, it can be concluded that if this ICT sensor network that detects and controls water, fertilizer, and pesticides can spread across the farms in Canada, the annual crop yield in Canada (shown in Figure 6)(Statistics Canada, 2019)may rise from 88 million tonnes to 98 million tonnes. Considering that Canada has been exporting more than half of the crops to the overseas demand side (Agriculture and Agri-Food Canada, 2019), this potential growth in crop production will help alleviate the demand around the world. 


\section{Estimated production of principal field crops of Canada \\ (metric tonnes)}

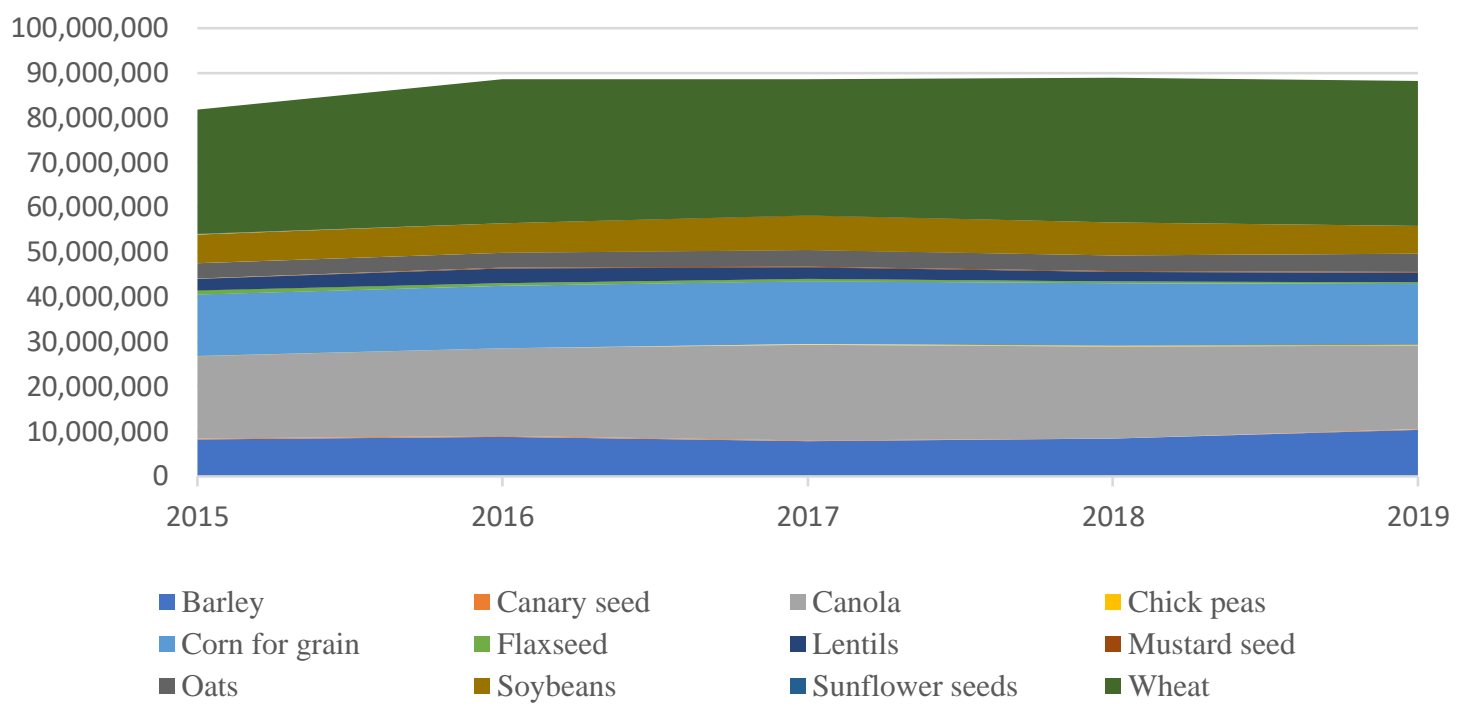

Figure 6. Estimated production of principal field crops of Canada (Statistics Canada, 2019)

Accordingly, with ICT sensor network, the amount of resources saved for agricultural production cannot be overlooked. In Canada, the annual total irrigation volume for crops was 2.05 million cubic metres in 2016 , rising to 2.95 million cubic metres in 2018 , a $43 \%$ increase (Statistics Canada, 2019).Fertilizer consumption per hectare of arable land in Canada was reported at $87.63 \mathrm{~kg}$ in 2016 . With $41,224,000$ hectares of arable land in Canada, the annual fertilizer consumption is estimated as 36 million tonnes in 2016, which has increased from 29 million tonnes in 2010, a 25\% increase (Index Mundi, 2020; World Bank, 2020). Only considering irrigation and fertilizer use, ICT sensor networks are expected to help Canada save irrigation water by 0.59 million tonnes, and fertilizer by 5.76 million tonnes, with increases in crop yield of 14 million tonnes.

As can be seen from the results above, since the consumption of water, fertilizer and pesticide can be controlled by ICT sensor networks, deploying this solution across the country in Canada is likely to have a huge positive influence on the crop yield and the environment.

\subsection{Conclusion and Limitation}

According to Food and Agriculture Organization of the United Nations, the growth in yield of rice in developing countries has been declining or stagnating for years since 2009. In 
south Asia, the annual yield of rice has dropped by $10 \%$ due to the primary and secondary damage to farmland due to effects of climate change. There are many reasons for the low yield, such as diseases and insect pests, soil erosion, and improper farming. In addition, limited research investment and transfer of scientific and technological practices have also put underdeveloped regions into inefficient agricultural production, and the lack of technology leaves their agricultural industry vulnerable (World Bank, 2017).

This study aimed to address the gap in knowledge from the few quantitative analyses of the performance of ICT sensor networks that reported simultaneous monitoring of water, fertilizer and pesticide (or some subset of these). In this study, the necessity and feasibility of utilizing ICT sensor networks in agriculture have been clarified.

The analysis shows that as a whole, ICT sensor networks can indeed effectively improve the use of agricultural resources, such as water, fertilizers and pesticides, and can also increase crop output by $16 \%$. If this technology can be widely used in developing countries or regions that rely heavily on agriculture as a source of income and livelihood, then farmers and the agricultural sector there can satisfy more of them with limited resources in a sustainable way.

Meanwhile, the cost of deploying, setting up and maintaining a network is often a stumbling block to prevent farmers from adopting ICT sensor networks. In fact, there are already some low-cost solutions, such as a basic version of the network designed by Polo et al. (2015). The total cost can be controlled within $\$ 1,000$, operating in a farm of around 100 ha.

Regarding the limitation of this study, the first is that the small amount of data has limited the development of this study. Although the research on the combination of ICT and agriculture is not a new topic, most of the literature that can be found now does not include quantitative statements regarding the performance of their equipment. Therefore, it is not easy to find a lot of information about the performance of ICT sensor networks in agriculture. Attempts have been made to reach out to the authors and researchers for more detailed information regarding the research questions, but very few replies were received.

Another limitation of this study is that the original meta-analysis was not completed. Judging from the publications I've been exposed to regarding the application of the ICT sensor network in agriculture, no researcher provided information about the experimental group and 
the control group in their articles, and the standard deviation used to calculate meta-analysis is even more rare. Similarly, I wrote some emails to these researchers, but unfortunately there are few responders and insufficient data to support this analysis. In the end, the focus of this research was on the simulation of farmland equipped with ICT sensor network equipment. 


\subsection{Future recommendations}

This study can be a very small part of future studies looking to provide optimal allocation of agricultural resources in crop production. The perspective of this research is relatively macro. It is based on the existing research conclusions of previous people. In the future, more micro experiments can be conducted. For example, ICT sensor networks can be set up in situ to control irrigation and fertilizer application on farmland, and eventually figure out the best external conditions for planting. To be specific, a piece of farmland can be divided into a grid, and ICT sensor networks will be deployed for monitoring and controlling the amount of agricultural input. By comparing crop yields under different conditions, find out the most suitable external environmental parameters for certain farmland and crops.

In the long run, after collecting and analyzing many years of data, ICT can be used to match the right environment with cultivars, to increase understanding of the interactions between genotypes and the environment, and to adapt planting strategies to constantly changing climate. 


\section{Appendices}

Appendix A: Tables and figures of the details of ICT sensor networks

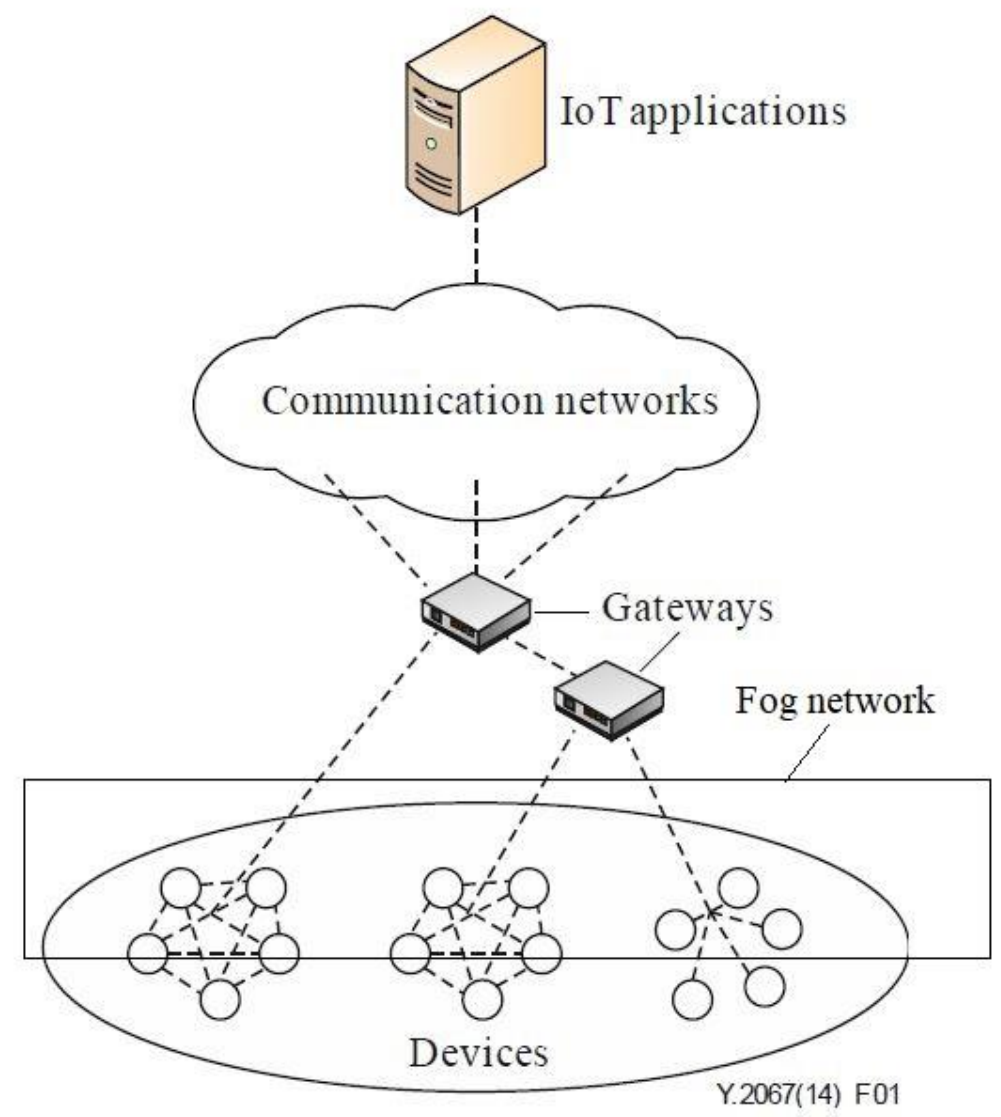

Figure A1. Architecture of wireless sensor networks based on fog network (Telecommunication Standardization Sector of International Telecommunication Union, 2014) 

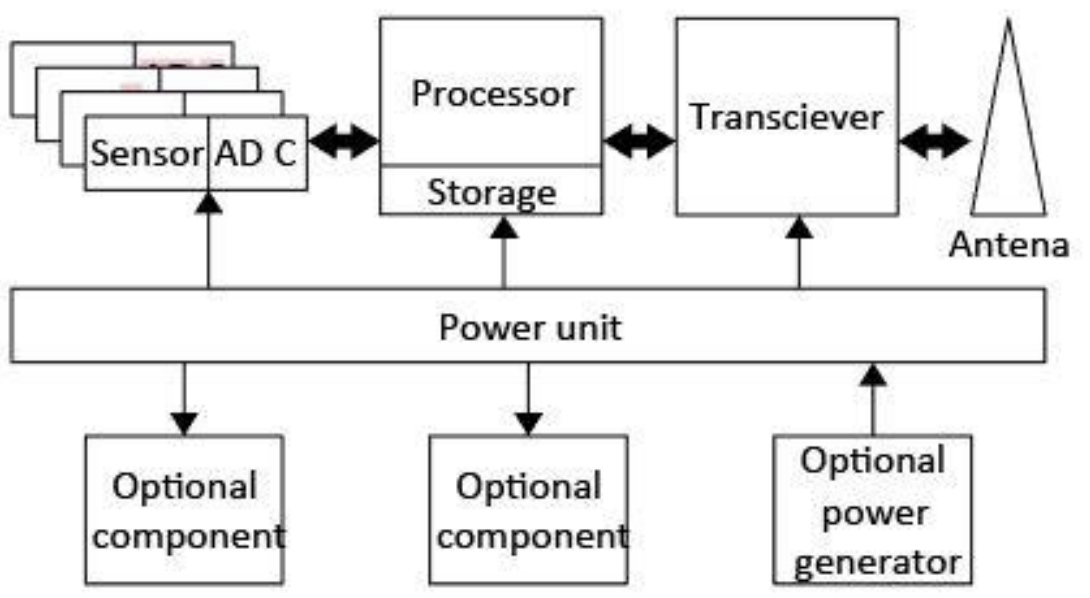

Figure A2. Major components of nodes in ICT sensor networks (Sliva, 2008)

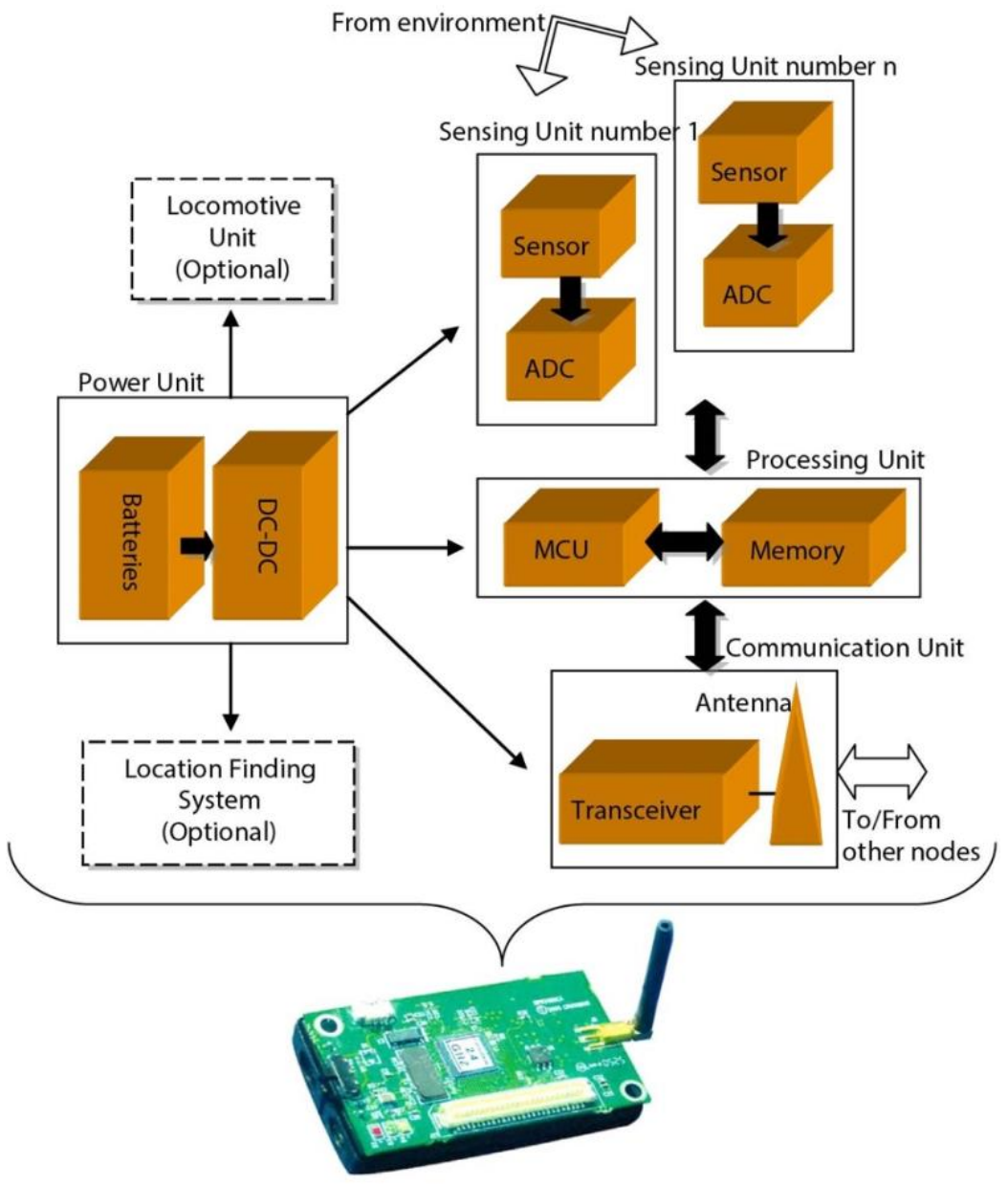

Figure A3. Architecture of nodes in ICT sensor networks (El-Kader \& El-Basion, 2013) 


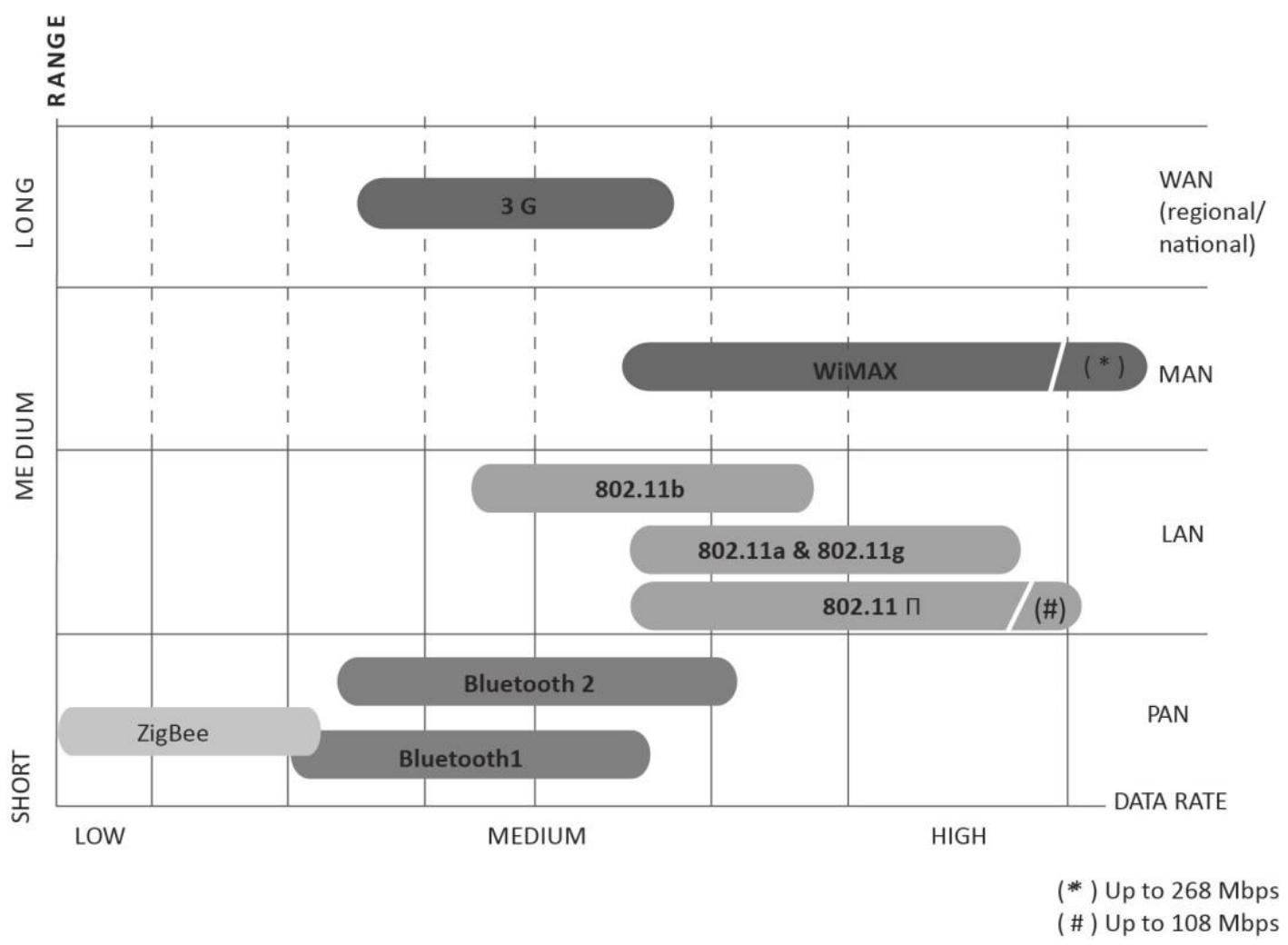

Figure A4. Comparison of available wireless protocols (Sohraby, Minoli, \& Znati, 2007)

Table A1. Comparison of communication protocols (Ojha, Misra, \& Raghuwanshi, 2015)

\begin{tabular}{llllll}
\hline Parameter & ZigBee & WiFi & Bluetooth & GPRS/3G/4G & WiMAX \\
\hline Standard & IEEE 802.15.4 & IEEE $802.11 \mathrm{a}, \mathrm{b}, \mathrm{g}, \mathrm{n}$ & IEEE 802.15 .1 & - & IEEE 802.16a,e \\
Data rate & $20-250 \mathrm{kbps}$ & $2-54 \mathrm{Mbps}$ & $1-24 \mathrm{Mbps}$ & $50-100 \mathrm{kbps} / 200 \mathrm{kbps} / 0.1-1 \mathrm{Gbps}$ & $0.4-1 \mathrm{Gbps}(\mathrm{stationary)}$ \\
& & & & & \\
& & & & & \\
Transmission range & $10-20 \mathrm{~m}$ & $20-100 \mathrm{~m}$ & $8-10 \mathrm{~m}$ & Entire GSM coverage area & smaller than 650 km \\
Energy consumption & Low & High & Medium & Medium & Medium \\
Cost & Low & High & Low & Medium & High \\
\hline
\end{tabular}


Table A2. Examples of ecological sensors (Gong, 2010)

\begin{tabular}{|c|c|c|c|c|}
\hline Type & Field & Price & Performance & Power consumptic \\
\hline \multirow{6}{*}{ Physical } & Temperature & Medium & Reliable & Low \\
\hline & Relative humidity & Medium & Reliable & Low \\
\hline & Leaf humidity & Cheap & Reliable & Low \\
\hline & Soil temperature & Cheap to medium & Correction required & Low \\
\hline & Total radiation & Medium & Correction required & Low \\
\hline & Sonic anemometer & Medium to Expensive & Reliable & Medium \\
\hline \multirow{5}{*}{ Chemical } & Atmospheric $\mathrm{CO}_{2}$ & Expensive & Correction required & Medium \\
\hline & Soil $\mathrm{CO}_{2}$ & Medium & Correction required & Low \\
\hline & Soil $\mathrm{CO}_{2}$ flux & Expensive & Correction required & Medium \\
\hline & Nitrates sensor & Expensive & \multirow{2}{*}{\multicolumn{2}{|c|}{$\begin{array}{l}\text { Not applicable for terrestrial ecosysten } \\
\text { Not applicable for terrestrial ecosysten }\end{array}$}} \\
\hline & Phosphorus sensor & Expensive & & \\
\hline & Root imager & Expensive & Reliable & diverse \\
\hline & Plant juice flow sensor & Medium & \multicolumn{2}{|c|}{ Control system and correction require } \\
\hline Biological & Sound sensor & Medium & Reliable & Medium \\
\hline
\end{tabular}




\section{Bibliography}

Abruña-Rodríguez, F., Vicente-Chandler, J., Rivera, E., \& Rodríguez, J. (1982). Effect of Soil Acidity Factors on Yields and Foliar Composition of Tropical Root Crops. Soil Science Society of America Journal, 46(5), 1004-1007.

Accenture. (2017). Digital agriculture: Improving profitability. Accenture.

Agriculture and Agri-Food Canada. (2019). Canada: Outlook for principal field crops. Agriculture and Agri-Food Canada.

Alam, M. M., Malik, H., Khan, M. I., Pardy, T., Kuusik, A., \& Le Moullec, Y. (2018). A survey on the roles of communication technologies in IoT-based personalized healthcare applications. IEEE Access, 6, 36611-36631.

Arakeri, M. P., Arun, M., \& Padmini, R. K. (2015). Analysis of Late Blight Disease in Tomato Leaf Using Image Processing Techniques. International Journal of Engineering and Manufacturing, 12-22.

Ashraf, M., \& Saeed, M. M. (2006). Effect of improved cultural practices on crop yield and soil salinity under relatively saline groundwater applications. Irrigation and Drainage Systems, 20(1), 111-124.

Atfarm. (2018, October). Crop monitoring made easy. Retrieved from Atfarm: https://www.at.farm/crop-monitoring-solution/

Atherton, B. C., Morgan, M., Shearer, S. A., Stombaugh, T. S., \& Ward, A. D. (1999). Sitespecific farming: A perspective on information needs, benefits and limitations. Journal of soil and water conservation, 54(2), 455-461.

Barbedo, J. G. (2013). Digital image processing techniques for detecting, quantifying and classifying plant diseases. SpringerPlus, 2(1), 660.

Bausch, W. C., \& Delgado, J. A. (2003). Ground-Based Sensing of Plant Nitrogen Status in Irrigated Corn to Improve Nitrogen Management. In Digital Imaging and Spectral Techniques: Applications to Precision Agriculture and Crop Physiology (pp. 151-163). American Society of Agronomy,

Best, J. (2018, November 14). IoT and the NHS: Why the Internet of Things will create a healthcare revolution. Retrieved from ZDNET: https://www.zdnet.com/article/iot-andthe-nhs-why-the-internet-of-things-will-create-a-healthcare-revolution/

Bishop, P. (2004). Pollution Prevention. Waveland Press, Inc. 
Boissard, P., Martin, V., \& Moisan, S. (2008). A cognitive vision approach to early pest detection in greenhouse crops. computers and electronics in agriculture. Computers and Electronics in Agriculture, 62(2), 81-93.

Bongiovanni, R., \& Lowenberg-Deboer, J. (2004). Precision agriculture and sustainability. Precision Agriculture, 5(4), 359-387.

Brase, T. A. (2006). Precision agriculture. Thomson.

Breiman, L. (2001). Random Forests. Machine Learning, 45(1), 5-32.

Brockwell, S. E., \& Gordon, I. R. (2001). A comparison of statistical methods for meta-analysis. Statistics in medicine, 20(6), 825-840.

Calzadilla, A., Rehdanz, K., \& Tol, R. S. (2010). The economic impact of more sustainable water use in agriculture: A computable general equilibrium analysis. Journal of Hydrology, 384(3-4), 292-305.

Carter, E. K., Melkonian, J., Riha, S. J., \& Shaw, S. B. (2016). Separating heat stress from moisture stress: analyzing yield response to high temperature in irrigated maize. Environmental Research Letters, 11(9), 094012.

Chen, L., Huang, S., Sun, Y., Zhu, E., \& Wang, K. (2019). Rapid Identification of Potassium Nutrition Stress in Rice Based on Machine Vision and Object-Oriented Segmentation. Journal of Spectroscopy.

Chen, L., Lin, L., Cai, G., Sun, Y., Huang, T., Wang, K., \& Deng, J. (2014). Identification of nitrogen, phosphorus, and potassium deficiencies in rice based on static scanning technology and hierarchical identification method. PloS one, 9(11).

Cisco. (2015). Fog computing and the internet of things: Extend the cloud to where the things are. Retrieved from Cisco: https://www.cisco.com/c/dam/en_us/solutions/trends/iot/docs/ computing-overview.pdf

Costa, F. G., Ueyama, J., Braun, T., Pessin, G., Osório, F. S., \& Vargas, P. A. (2012). The use of unmanned aerial vehicles and wireless sensor network in agricultural applications. 2012 IEEE International Geoscience and Remote Sensing Symposium (pp. 5045-5048). IEEE.

Cremer, C., Eichhammer, W., Friedewald, M., Georgieff, P., Rieth-Hoerst, S., Schlomann, B., . . Huser, A. (2010). Energy Consumption of Information and Communication Technology (ICT) in Germany up to 2010. Summary of the final report. Germany. 
Datir, S., \& Wagh, S. (2014). Monitoring and Detection of Agricultural Disease using Wireless Sensor Network. International Journal of Computer Applications, 87(4), 0975-8887.

Dholu, M., \& Ghodinde, K. A. (2018). Internet of things (iot) for precision agriculture application. 2nd International Conference on Trends in Electronics and Informatics (ICOEI) (pp. 339-342). IEEE.

Dobor, L., Barcza, Z., Hlásny, T., Árendás, T., Spitkó, T., \& Fodor, N. (2016). Crop planting date matters: Estimation methods and effect on future yields. Agricultural and Forest Meteorology, 223, 103-115.

Elijah, O., Rahman, T. A., Orikumhi, I., Leow, C. Y., \& Hindia, M. N. (2018). An overview of Internet of Things (IoT) and data analytics in agriculture: Benefits and challenges. IEEE Internet of Things Journal, 5(5), 3758-3773.

El-Kader, S. M., \& El-Basion, B. M. (2013). Precision farming solution in egypt using the wireless sensor network technology. Egyptian Informatics Journal, 14(3), 221-233.

Es van, H., \& Woodard, J. (2017). Innovation in agriculture and food systems in the digital age. In S. Dutta, B. Lanvin, \& S. Wunsch-Vincent (Eds.), Global Innovation Index 2017: Innovation Feeding the World. World Intellectual Property Organization.

Fagas, G., Gammaitoni, L., Gallagher, J. P., \& Paul, D. (2017). Energy Challenges for ICT. In ICT-Energy Concepts for Energy Efficiency and Sustainability. BoD-Books on Demand.

Faiçal, B., Costa, F., Pessin, G., Ueyama, J., Freitas, H., Colombo, A., . . Braun, T. (2014). The use of unmanned aerial vehicles and wireless sensor networks for spraying pesticides. Journal of Systems Architecture, 60(4), 393-404.

Fanucci, L., Saponara, S., Bacchillone, T., Donati, M., Barba, P., Sánchez-Tato, I., \& Carmona, C. (2012). Sensing devices and sensor signal processing for remote monitoring of vital signs in CHF patients. IEEE Transactions on Instrumentation and Measurement, 62(3), 553-569.

Fortino, G., Parisi, D., Pirrone, V., \& Di Fatta, G. (2014). BodyCloud: A SaaS approach for community body sensor networks. Future Generation Computer Systems, 35, 62-79.

Gaffney, O. (2014). Sustainable Development Goals Improving human and planetary wellbeing. Global Change(82), 20-23. Retrieved from http://www.igbp.net/download/18.62dc35801456272b46d51/1399290813740/NL82SDGs.pdf 
Galar, D., \& Kumar, U. (2017). Sensors and Data Acquisition. In eMaintenance (pp. 1-72). Academic Press.

Gastélum-Barrios, A., Bórquez-López, R. A., Rico-García, E., Toledano-Ayala, M., \& SotoZarazúa, G. M. (2011). Tomato quality evaluation with image processing: A review. African Journal of Agricultural Research, 6(14), 3333-3339.

Gazey, C., \& Azam, G. (2018, September 17). Effects of soil acidity. Retrieved from Department of Primary Industries and Regional Development's Agriculture and Food, Government of Western Australia: https://www.agric.wa.gov.au/soil-acidity/effectssoil-acidity

Geeta, D. D., Nalini, N., \& Biradar, R. C. (2013). Fault tolerance in wireless sensor network using hand-off and dynamic power adjustment approach. Journal of Network and Computer Applications, 36(4), 1174-1185.

Glass, G. V. (1976). Primary, secondary, and meta-analysis of research. Educational researcher, 5(10), 3-8.

Gong, P. (2010). Progress in recent environmental applications of wireless sensor networks. Journal of Remote Sensing, 387-395.

Grantz, D. A. (1990). Plant response to atmospheric humidity. Plant, Cell and Environment, 13(7), 667-679.

Gu, Y., Zhang, X., Tu, S., \& Lindström, K. (2009). Soil microbial biomass, crop yields, and bacterial community structure as affected by long-term fertilizer treatments under wheat-rice cropping. European Journal of Soil Biology, 45(3), 239-246.

Gutiérrez-Madroñal, L., La Blunda, L., Wagner, M. F., \& Medina-Bulo, I. (2019). Test event generation for a fall-detection IoT system. IEEE Internet of Things Journal, 6(4), 66426651 .

Hebei Academy of Social Sciences. (2017). In Macroeconomic Situation and Policy Guide 20017 (p. 22). Shijiazhuang: China Financial and Economic Publishing House.

Honkavaara, E., Saari, H., Kaivosoja, J., Pölönen, I., Hakala, T., Litkey, P., . . L., P. (2013). Processing and assessment of spectrometric, stereoscopic imagery collected using a lightweight UAV spectral camera for precision agriculture. Remote Sensing, 5(10), 5006-5039. 
Horning, N. (2008). Remote Sensing. In S. E. Jørgensen, \& B. D. Fath (Eds.), Encyclopedia of Ecology (pp. 2986-2994). Academic Press.

Hoskinson, R. L., Hess, J. R., \& Fink, R. K. (1999). A decision support system for optimum use of fertilizers. 2nd European Conference on Precision Agriculture. Idaho Falls.

IEEE Standard Association. (2020, March). IEEE Standard Association. Retrieved from IEEE Standard Association: https://standards.ieee.org/standard/802_11-2016.html

Index Mundi. (2020). Canada - Arable land (hectares). Index Mundi.

InfoQ. (2019, December 19). Fintech feast (5): IoT applciations in banking. Retrieved from InfoQ: https://www.infoq.cn/article/Yevp6zYlMMzjtyHkEy9U

Jangra, A. (2010). Wireless Sensor Network (WSN): Architectural Design issues and Challenges. International Journal on Computer Science and Engineering, 2(9), 30893094.

Jawad, H. M., Nordin, R., Gharghan, S. K., Jawad, A. M., \& Ismail, M. (2017). EnergyEfficient Wireless Sensor Networks for Precision Agriculture: A Review. Sensors, 17, 1781.

Jiber, Y., Harroud, H., \& Karmouch, A. (2011). Precision agriculture monitoring framework based on WSN. 2011 7th International Wireless Communications and Mobile Computing Conference (pp. 2015-2020). Istanbul: IEEE.

Jones, N. (2018). How to stop data centres from gobbling up the world's electricity. Nature, 561(7722), 163-166.

Ju, X. T., Kou, C. L., Christie, P., Dou, Z. X., \& Zhang, F. S. (2007). Changes in the soil environment from excessive application of fertilizers and manures to two contrasting intensive cropping systems on the North China Plain. Environmental Pollution, 145(2), 497-506.

Kalaivani , T., Allirani, A., \& Priya, P. (2011). A survey on zigbee based wireless sensor networks in agriculture. Trendz in Information Sciences and Computing, $20113 \mathrm{rd}$ International Conference (pp. 85-89). IEEE.

Karunanithi, R., Szogi, A., Bolan, N. S., Naidu, R., Ok, Y. S., Krishnamurthy, S., \& Seshadri, B. (2016). Phosphorus Recovery From Wastes. In Environmental Materials and Waste (pp. 687-705). Academic Press. 
Kashiha, M. A., Bahr, C., Berckmans, D., \& Gates, R. S. (2014). Performance of an image analysis processing system for hen tracking in an environmental preference chamber. Poultry science, 93(10), 2439-2448.

Khakural, B. R., Robert, P. C., \& Mulla, D. J. (1996). Relating corn/soybean yield to variability in soil and landscape characteristics. Precision agriculture, 117-128.

Khanboubi, F., Boulmakoul, A., \& Tabaa, M. (2019). Impact of digital trends using IoT on banking processes. Procedia Computer Science, 151, 77-84.

Krebs, A. H. (1984). Agriculture in our lives: an introduction to agricultural business and natural resources. Vero Media Inc.

Krishna, K. R. (2016). Precision farming: soil fertility and productivity aspects. Apple Academic Press.

Kucharik, C. J. (2008). Contribution of planting date trends to increased maize yields in the central United States. Agronomy Journal, 100(2), 328-336.

Laplante, P., \& Laplante, N. (2016). The Internet of Things in Healthcare: Potential Applications and Challenges. IT Professional, 18(3), 2-4.

Latha, M., Poojith, A., Reddy, B. A., \& Kumar, G. V. (2014). Image Processing in Agriculture. International journal of innovative research in electrical, electronics, instrumentation and control engineering, 2(6).

Lazarcik, G. (1963). Factors affecting production and productivity in czechoslovak agriculture, 1934-38 and 1946-60. American Journal of Agricultural Economics, 45(1), 205-218.

Lipsey, M. W., \& Wilson, D. B. (2001). Practical meta-analysis. Sage Publications, Inc.

Mateo-Sagasta, J., Zadeh, S. M., \& Turral, H. (2017). Water pollution from agriculture: a global review. Rome: Food and Agriculture Organization of the United Nations. Retrieved from Food and Agriculture Orgnization of the United Nations: http://www.fao.org/3/a-i7754e.pdf

Matson, P. A., Naylor, R., \& Ortiz-Monasterio, I. (1998). Integration of environmental, agronomic, and economic aspects of fertilizer management. Science, 280(5360), 112115.

McDermott-Wells, P. (2004). What is Bluetooth? IEEE Potentials, 23(5), 33-35. 
Meeradevi , A., \& Mundada, M. R. (2015). ZigBee Based Wireless Sensor Networks in Precision Agriculture - The Survey. International Journal of Application or Innovation in Engineering \& Management, 4(5).

Mohammadi, M. F., Jalali, S. G., Kooch, Y., \& Said-Pullicino, D. (2016). Slope gradient and shape effects on soil profiles in the northern mountainous forests of Iran. Eurasian soil science, 49(12), 1366-1374.

Moore, K., \& Bradley, L. K. (2018). North Carolina Extension Gardener Handbook. NC State Extension, College of Agriculture and Life Sciences, NC State University.

Mora, H., Gil, D., Terol, R. M., Azorín, J., \& Szymanski, J. (2017). An IoT-based computational framework for healthcare monitoring in mobile environments. Sensors, 17(10), 2302.

Nack, F. (2019, February 1). An overview on wireless sensor networks. Retrieved from Institute of Computer Science (ICS), Freie Universität Berlin: http://www.mi.fuberlin.de/inf/groups/ag-tech/teaching/2008-

09_WS/S_19565_Proseminar_Technische_Informatik/nack09verview.pdf

Nie, C. (2008). Agricultural environmental resource protection. Guangzhou: Chemical Industry Press.

Nuaymi, L. (2007). WiMAX: technology for broadband wireless access. John Wiley \& Sons.

Obi, F. O., Ugwuishiwu, B. O., \& Nwakaire, J. N. (2016). Agricultural waste concept, generation, utilization and management. Nigerian Journal of Technology (NIJOTECH), $35(4), 957-964$.

Ojha, T., Misra, S., \& Raghuwanshi, N. S. (2015). Wireless sensor networks for agriculture: The state-of-the-art in practice and future challenges. Computers and Electronics in Agriculture, 118, 66-84.

Oquist, G. (1983). Effects of low temperature on photosynthesis. Plant, Cell and Environment, 6(4), 281-300.

Pathiratna, L. S., Joseph, K. D., \& Perera, M. K. (2004). The effect of some cultural practices on the growth and yield of the medicinal plant Aerva lanata (1). Juss. Ex schult.(polpala). Ceylon Journal of Science, 32, 67-74.

Patil, S. B. (2011). Betel Leaf Area Measurement Using Image Processing. International Journal on Computer Science and Engineering, 3(7), 2656-2660. 
Patil, V. C., Al-Gaadi, K. A., Madugundu, R., Tola, E. H., Marey, S., Aldosari, A., ... Gowda, P. H. (2015). Assessing agricultural water productivity in desert farming system of Saudi Arabia. IEEE Journal of Selected Topics in Applied Earth Observations and Remote Sensing, 8(1), 284-297.

Pedregosa, F., Varoquaux, G., Gramfort, A., Michel, V., Thirion, B., Grisel, O., .. . Duchesnay, E. (2011). Scikit-learn: Machine Learning in Python. Journal of Machine Learning Research, 12, 2825-2830.

Peng, S., \& Zheng, F. (1999). Meta-Analysis: A Graet Revolution in Review. Chinese Journal of Ecology, 18(6), 65-70.

Pierre, W. H. (1928). Nitrogenous fertilizers and soil acidity. I. Effect of various nitrogenous fertilizers on soil reaction. Journal of the American Society of Agronomy, 20(3), 254269.

Polo, J., Hornero, G., Duijneveld, C., García, A., \& Casas, O. (2015). Design of a low-cost Wireless Sensor Network with UAV mobile node for agricultural applications. Computers and Electronics in Agriculture, 119, 19-32.

Pradana, Z. H., Hidayat, B., \& Darana, S. (2016). Beef cattle weight determine by using digital image processing. 2016 International Conference on Control, Electronics, Renewable Energy and Communications (pp. 179-184). IEEE.

Radmand, P., Talevski, A., Petersen, S., \& Carlsen, S. (2010). Comparison of industrial WSN standards. 4th IEEE International Conference on Digital Ecosystems and Technologies (pp. 632-637). IEEE.

Rahman, M. u., Rahman, S., Mansoor, S., Deep, V., \& Ashkaar, M. (2016). Implementation of ICT and Wireless Sensor Networks for Earthquake Alert and Disaster Management in Earthquake Prone Areas. Procedia Computer Science, 85, 92-99.

Ramírez-García, R., Gohil, N., \& Singh, V. (2019). Recent advances, challenges, and opportunities in bioremediation of hazardous materials. In Phytomanagement of Polluted Sites (pp. 517-568). Elsevier.

Reinecke, M., \& Prinsloo, T. (2017). The influence of drone monitoring on crop health and harvest size. 2017 1st International Conference on Next Generation Computing Applications (NextComp) (pp. 5-10). Mauritius: IEEE. 
Sakthipriya, N. (2014). An effective method for crop monitoring using wireless sensor network. Middle-East Journal of Scientific Research, 20(9), 1127-1132.

Satran, M. (2018, May 31). Best Practices for Energy Efficiency. Retrieved from Microsoft Windows Dev Center: https://docs.microsoft.com/enus/windows/win32/win7appqual/energy-efficiency-best-practices

Savci, S. (2012). An agricultural pollutant: chemical fertilizer. International Journal of Environmental Science and Development, 3(1), 73.

Schwarzenbach, R. P., Egli, T., Hofstetter, T. B., Gunten, U., \& Wehrli, B. (2010). Global Water Pollution and Human Health. Annual Review of Environment and Resources, 5(1), 109-136.

scikit-learn. (2019). 3.2.4.3.2. sklearn.ensemble.RandomForestRegressor. Retrieved from scikit-learn: https://scikitlearn.org/stable/modules/generated/sklearn.ensemble.RandomForestRegressor.html\#skl earn-ensemble-randomforestregressor

Sessitsch, A., \& Mitter, B. (2015). 21st century agriculture: integration of plant microbiomes for improved crop production and food security. Microbial biotechnology, 8(1), 32-33.

Shamshiri, R. R., Weltzien, C., Hameed, I. A., Yule, I. J., Grift, T. E., Balasundram, S. K., . . Chowdhary, G. (2018). R Shamshiri, Redmond, et al. "Research and development in agricultural robotics: A perspective of digital farming. Int J Agric \& Biol Eng, 11(4).

Shuja, J., Madani, S., Bilal, K., Hayat, K., Khan, S., \& Sarwar, S. (2012). Energy-efficient data centers. Computing, 94, 973-994.

Singh, K., Gupta, I., \& Gupta, S. (2011). Classification of bamboo plant based on digital image processing by Central moment. 2011 International Conference on Image Information Processing (pp. 1-5). Shimla: 2011 International Conference on Image Information Processing.

Sliva, J. (2008). Technologies used in wireless sensor networks. International Conference on Systems, Signals and Image Processing (pp. 77-80). IEEE.

Sohraby , K., Minoli, D., \& Znati, T. (2007). Wireless sensor networks: technology, protocols, and applications. John Wiley \& Sons.

Stallings, W., \& Brown, L. (2018). Computer Security: Principles and Practice (4 ed.). Pearson. 
Statistics Canada. (2019). Table 38-10-0240-01: Irrigation volume by crop type (x 1,000). Statistics Canada.

Statistics Canada. (2020). Table 32-10-0359-01: Estimated areas, yield, production, average farm price and total farm value of principal field crops, in metric and imperial units. Statistics Canada.

Stekhoven, D. J., \& Bühlmann, P. (2012). MissForest—non-parametric missing value imputation for mixed-type data. Bioinformatics, 28(1), 112-118.

Tautges, N. E., Sullivan, T. S., Reardon, C. L., \& Burke, I. C. (2016). Soil microbial diversity and activity linked to crop yield and quality in a dryland organic wheat production system. Applied Soil Ecology, 108, 258-268.

Telecommunication Standardization Sector of International Telecommunication Union. (2014). ITU-T Rec. Y.2067 (06/2014) Common requirements and capabilities of a gateway for Internet of things applications, SERIES Y: GLOBAL INFORMATION INFRASTRUCTURE, INTERNET PROTOCOL ASPECTS AND NEXTGENERATION NETWORKS - Next Generation Networks - Frameworks. International Telecommunication Union, Geneva, Switzerland, Recommendation ITU-T Y, 2067.

Trivedi, P., Schenk, P. M., Wallenstein, M. D., \& Singh, B. K. (2017). Tiny Microbes, Big Yields: enhancing food crop production with biological solutions. Microbial biotechnology, 10(5), 999-1003.

United Nations. (2015). Goal 12: Ensure sustainable consumption and production patterns. Retrieved from United Nations: https://www.un.org/sustainabledevelopment/sustainable-consumption-production/

United Nations. (2016, August). Why it matters: Responsible Consumption and Production. Retrieved from United Nations: https://www.un.org/sustainabledevelopment/wpcontent/uploads/2016/08/12.pdf

United Nations Environment Programme. (2010). Clarifying Concepts on Sustainable Consumption and Production. United Nations Environment Programme.

United States Department of Agriculture. (n.d.). Agricultural Waste Management Systems. In U. S. Agriculture, Agricultural Waste Management Field Handbook (pp. 9-3). United States Department of Agriculture. 
United States Environmental Protection Agency. (2019). Nutrient Pollution: The Sources and Solutions: Agriculture. Retrieved from United States Environmental Protection Agency: https://www.epa.gov/nutrientpollution/sources-and-solutions-agriculture

Viechtbauer, W. (2010). Conducting meta-analyses in R with the metafor package. Journal of Statistical Software, 36(3), 1-48.

Wang, J., Zhao, F., \& Ouyang, Z. (2010). Effects of the irrigation quantity on soil respiration in wheat field in filling stage. Acta Agriculturae Boreali-Sinica, 25(3), 186-189.

Wang, N., \& Li, Z. (2013). Wireless sensor networks (WSNs) in the agricultural and food industries. In Robotics and automation in the food industry (pp. 171-199). Woodhead Publishing.

Warpe, S. T., \& Pippal, R. S. (2016). A Study of Fertilizer Distribution System for Agriculture using Wireless Sensor Network. International Journal of Computer Applications, 147(2).

Weinstein, R. (2005). RFID: a technical overview and its application to the enterprise. 7(3), 2733.

Weisz, R., Fleischer, S., \& Smilowitz, Z. (1996). Site-specific integrated pest management for high value crops: Impact on potato pest management. Journal of Econ. Entomology, 501-509.

Weng, J., Huang, L., Liu, X., \& Sato, K. (2000). Acidification of soils and aluminum species in natural soil solution. China Environmental Science, 20(6), 501-505.

Wetzel, R. G. (2001). Limnology: lake and river ecosystems. Gulf Professional Publishing. Whiteley, W. (2002). The Use of Precision Farming Technologies in Crop Decision Making. 13th Congress (p. 7003). Wageningen: International Farm Management Association.

Williams, R. D., Ahuja, L. R., Naney, J. W., Ross, J. D., \& Barnes, B. B. (1987). Spatial trends and variability of soil properties and crop yield in a small watershed. Transactions of the ASAE, 30(6), 1653-1660.

Wilson, D. B. (2001). Practical Meta-Analysis Effect Size Calculator . Retrieved from Campbell Collaboration: http://www.campbellcollaboration.org/escalc/html/EffectSizeCalculator-Home.php 
Wongsriworaphon, A., Pathumnakul, S., \& Arnonkijpanich, B. (2012). Image analysis for pig recognition based on size and weight. 2012 IEEE International Conference on Industrial Engineering and Engineering Management (pp. 856-860). IEEE.

World Bank. (2017). ICT in Agriculture. Washington, DC: World Bank.

World Bank. (2020). Canada - Fertilizer Consumption. Trading Economics.

World Commission on Environment and Development. (1987, March 20). Our Common Future. Retrieved from United Nations: https://sustainabledevelopment.un.org/content/documents/5987our-common-future.pdf

Wu, H. (2010). Review on Internet of Things: application and challenges. Journal of Chongqing University of Posts and Telecommunications(Natural Science Edition), 22(5), 526-531.

Xarvio Digital FArming Solutions. (2020, January). Xarvio Digital FArming Solutions. Retrieved from Xarvio Digital FArming Solutions: https://www.xarvio.com/global/en/FIELD-MANAGER.html

Xia, L. (2005). Basic Questions of Meta-analysis Methods. Journal of Shanxi Normal University, 32(3), 34-38.

Xiong, B., Luo, Q., Lv, J., \& Yang, L. (2008). Study of digital management system of milking process on large-sized dairy farm. Agricultural Sciences in China, 47(2), 1022-1028.

Xu, G., Zhang, F., Shah, S. G., Ye, Y., \& Mao, H. (2011). Use of leaf color images to identify nitrogen and potassium deficient tomatoes. Pattern Recognition Letters, 32(11), 15841590.

Xu, R. (2015). Research progresses in soil acidification and its control. Soils, 47(2), 238-244.

Yadav, S., Swarnkar, K., Chauhan, T., \& Jain, R. (2012). How to improve food security and farming systems by using wireless sensor networks. Journal of Information Engineering and Applications, 20(6), 11-20.

Yang, C., Peterson, C. L., Shropshire, G. J., \& Otawa, T. (1998). Spatial variability of field topography andwheat yield in the palouse region of the Pacific Northwest. Transactions of the ASAE, 41(1), 17.

Yara. (2018, October). Yara Water Solution. Retrieved from Yara: https://www.yara.com/cropnutrition/products-and-solutions/precision-farming/yara-water-solution/ 
Yuan, B., Sun, X., You, R., Liu, F., \& Li, W. (2018). The Effect of Emotion on Trust: A Systematic Review and Meta-Analysis. Studies of Psychology and Behavioral, 16(5), 632-6643.

Zhang, B., Luo, X., Lan, Y., Huang, Z., Zeng, M., \& Li, J. (2015). Agricultural environment monitor system based on UAV and wireless sensor networks. Transactions of the Chinese Society of Agricultural Engineering, 31(17), 176-182.

Zhao, J. C., Zhang, J. F., Feng, Y., \& Guo, J. X. (2010). The study and application of the IOT technology in agriculture. 3rd International Conference on Computer Science and Information Technology.2, pp. 462-465. IEEE. 